\title{
Synoptic analysis of the most durable pollution and clean waves during 2009-2019 in Tehran City (capital of Iran)
}

\author{
Farzaneh Jafari Hombari ${ }^{1} \cdot$ Farshad Pazhoh $^{2}$ (D)
}

Received: 25 January 2021 / Accepted: 11 August 2021 / Published online: 20 August 2021

(c) The Author(s), under exclusive licence to Springer Nature B.V. 2021

\begin{abstract}
The present study was done to analyze and compare synoptic conditions during the most durable pollution and clean waves (MDPW and MDCW) in Tehran City (capital of Iran). For this purpose, air quality index (AQI) data were first obtained during 2009-2019 from the Tehran Air Quality Control Company in Tehran Province. Then, a threshold of $(\mathrm{AQI} \leq 101)$ representing a polluted and unhealthy atmosphere was considered as MDPW, and a threshold of $(\mathrm{AQI} \leq 50)$ representing a clean (good) air was selected as MDCW in Tehran City by identifying the polluted days. The results showed the presence of MDPW during 43 polluted days from November 21, 2010 to January 2, 2011. Intensity and frequency of the polluted days during statistical period showed a decreasing trend that coincided with an increasing trend of precipitation. Analysis of synoptic conditions occurred during 43 days of MDPW indicated penetration of Siberian high-pressure from the east at sea level and extension of sub-tropical anticyclone in mid-level from the west that led to development of an anticyclone circulation with descending and converging flow in Iran and surrounding region. As a result, a calm and sustainable climate and stable concentration of pollutants were observed throughout Tehran City. Backward trajectory of sources and entry route of the polluted air to Tehran City during peak days of pollution showed that desert regions of southern Iraq and central Iran along the southern and southwestern parts played a major role in increasing concentration of pollutants during occurrence of durable wave. Different routes were observed in entry of dusty and the polluted air to Tehran City according to hybrid single-particle Lagrangian integrated trajectory (HY SPLIT) model, but in most of peak days, the areas that were near and adjacent to Tehran City with height of less than $1000 \mathrm{~m}$ played a greater role in particle transport. Investigation of instability indices during MDPW showed that in most days of pollution, values of instability intensity were classified into weak class and lower troposphere (1000-850 hPa) compared to higher levels, and degree of stability and calmness of the atmosphere was more. So that, the highest frequency of temperature inversions occurred near the earth's surface.
\end{abstract}

Keywords Polluted air $\cdot$ Air quality index $\cdot$ Durable wave $\cdot$ Stable atmosphere $\cdot$ Tehran

Farshad Pazhoh

Farshad.Pazhooh44@gmail.com

1 Department of Physical Geography, Shahid Beheshti University, Tehran, Iran

2 Department of Physical Geography, Kharazmi University, Tehran, Iran 


\section{Introduction}

Effects of air pollution on humans' life have become tangible since humans' habitation was developed in the form of the centralized and stable communities (Meshkini et al. 2017; Liu et al. 2017). Gradually, with passing of time and increases in development (notably with the beginning of Industrial Revolution), air pollution has become an international issue, especially in the recent years (Perkins 1974; Lou et al. 2019). Air pollution is one of the most important human hazards, particularly in metropolises where study of its effects is one of the major priorities in climate research. The atmospheric pollution is considered in the field of climatology in a way that following changes in Iran's climate with the increase in temperature and decrease in precipitation, especially in the recent decades, various climatic hazards have increased significantly including the increased frequency of the polluted days (Mousavi et al. 2020).

Study of the effects of air pollution is very important to determine how technological development has spread pollutants and increased pollution levels in the recent decades, making this a major priority in climate research. The increases in urbanization and living standards, and development of industries have also elevated concentration of pollutants to dangerous levels (Wu et al. 2017; Ravindra et al. 2001).

In the case of Tehran City, air pollution causes damages in terms of both humans' health and associated costs; and it has been estimated that some of these costs will be increased by $\$ 16,224$ (USD) daily with every unit increase in PM10 (particulate matter) and also will be increased by $\$ 28,816$ (USD), $\$ 1,927$ (USD), and $\$ 7,739$ (USD) per unit increase in carbon monoxide (CO), nitrogen dioxide (NO2), and sulfur dioxide (SO2), respectively (Karimzadegan et al. 2008). In 2013, air pollution alone caused 4,460 deaths in Tehran City (Mawer 2014). Pollution is also the most important environmental risk factor in emergence and progression of some diseases including lung cancer, asthma, Alzheimer's and Parkinson's diseases, as well as psychological complications, and devastating effects on fetus and many others (Ghorani-Azam et al. 2016; Liu et al. 2016; Magari et al. 2001). Kermani et al. (2018) found that the total number of deaths was more than 53,000 people as a result of air pollution during 2005-2014 in Tehran City of which more than 42,000 deaths were related to cardiovascular and respiratory diseases. During this period, air quality index (AQI) rate was increased by $11.8 \%$ where PM 2.5 and PM 10 pollutants played the greatest role in weakening air quality in Tehran City and its resulting hazards (Saniei et al. 2016).

Rapid growth of populations in metropolises creates many issues for sustainable development. Environmental pollution, reduction of vegetation cover, and rising temperatures in the recent years in Tehran City have created an environmental problem highlighting the need for a solution (Bidokhti and Shariepour 2010). Meteorological conditions and changes in physical and dynamic properties of the atmosphere play an important role in levels of air pollution. Winds blowing at low levels of the atmosphere near the earth's surface are the most important factor in dispersing and transmitting air pollution; and vertical thermal gradients play a determinant role in creation of upward movement and vertical diffusion of atmospheric pollutants (Khoshhal-Dastjerdi et al. 2012). Perkins defines air pollution as the presence of one or more pollutants, such as dust, fumes, gases, mist, and smoke in the air that are dangerous to humans', plants', or animals' life (Hosseinzadeh et al. 2013). In fact, these upward movements, transporting the polluted particles and dust, occur due to lack of moisture. But, when the two main conditions of precipitations, namely humidity and ascent, are provided, precipitation is expected to occur (Alijani 2007). In this 
regard, Di and Li (2019) also believe that with the increase in precipitation, the amount of AQI decreases and precipitation actually has a washing and purifying effect on pollutant particles and dust.

In a study on air pollution trends in Tehran City from 2005 to 2014, Jamaati et al. (2018) showed that each of the pollutants had an increasing trend, which caused a reduction in the number of healthy days and rapidly increased the number of unhealthy days during the most recent years. Rainham et al. (2005) studied synoptic meteorological patterns and the relationship between air pollution and mortality rate in humans. Specifically, their results showed that hot and dry air masses had the highest concentrations of pollution, while cold wet and cold dry masses, associated with conditions, such as low temperatures and cloudy air conditions, had the lowest concentrations of pollution.

Gao et al. (2011) categorized seven polluted urban clusters based on China's daily air pollution index utilizing remote-sensing data. According to their studies, severe pollution was observed in all the studied cities in winter. The increasing trend of pollution in northern cities was mainly due to human activities and climatic conditions. While in southern cities, the increase in winter pollution was generally more influenced by climatic conditions. Adame et al. (2012) reported that the widespread increase in air pollution in southwestern regions of the Iberian Peninsula in August 2006 was attributed to a large-scale fire occurred in northwestern part of the peninsula and transfer of pollution to southern regions. Hosseinzadeh et al. (2013) investigated synoptic patterns influencing air pollution in the Mashhad metropolis (Razavi Khorasan Province, Iran). Their results showed that advection of cold air from upper latitudes and strengthening of thermal high pressures of sea level caused a severe decrease in temperature and increased air pollution in Mashhad City, northeastern Iran. Khoshhal-Dastjerdi et al. (2012) introduced the existence of Sudan and Gang low pressures at the sea level as synoptic causes regarding occurrence of dust storms and deep trough of the Mediterranean, Red Sea trough and Azores sub-tropical anticyclone were the most important synoptic systems influencing dust transfer to west of Iran and the study area. Bidokhti and Shariepour (2010) investigated air pollution status of Tehran City in relation to meteorological conditions of upper atmosphere and concluded that severe pollution is associated with the increase in surface pressure, inertia conditions in the atmosphere, and the decreased wind velocity and also a relative increase in atmosphere temperature. Lashkari and Hedayat (2006) identified four consecutive patterns of temperature inversions in Tehran City that resulted in severe air pollution. Ranjbar-Saadatabadi et al. (2005) in a case study on Tehran's thermal island and its numerical simulation concluded that according to results of prediction model and the observed values of climatic elements and pollution, it is possible to predict air pollution in Tehran City in the case of prediction of temperature and wind fields.

Delkash and Mir (2016) believed that replacing new vehicles with old ones in Tehran City could reduce concentrations of carbon monoxide by $53 \%$, organic carbon by $52 \%$, and methane by $58 \%$ and consequently improve air quality. Finardi and Pellegrini (2002) investigated synoptic conditions of a case of very severe urban air pollution in the Po Valley, Milan City (Italy) and found that local temperature and humidity had a more important role in intensity changes and extent of pollution than other climatic elements. Also, the existence of a strong anticyclone at $850 \mathrm{hPa}$ with advection of hot air played a significant role in occurrence of all the polluted days. Vardoulakis and Kassomenos (2008), in a study conducted in cities of Athens (Greece) and Birmingham (England) determined that during cold season, there was a positive correlation between PM10, CO, and NO3 pollutants and solar radiation and there was a negative correlation between PM10, ozone, and wind velocity and precipitation and 
this correlation was weakened during warm season. Also, investigation of both acute pollutions of PM2.5 and PM10 in the two cities showed that most of these periods were of trans-local origin in Birmingham City and they were of local origin in Athens City. In a study on assessing temperature inversion indices of Tehrans' boundary layer (Tavousi and Hossein-Abadi 2017) found that severe inversion occurred in autumn and winter and days with inversion durability can play a major role in air stability and the increase in pollution in levels near to sea surface especially in cold seasons of year. In a study on severe pollution in Santiago City (Chile), Munoz and Corral (2017) stated that climatic conditions can play an important role in changing air quality so that there is a significant relationship between 10-m wind speed and height of integration layer with improving and weakening of air quality as a ventilator. Rezaei et al. (2018) in a research about spatial-temporal distribution of dust-induced aerosol in Iran based on satellite data found that the highest frequency of aerosol occurs in southwest and southeast of Iran in July and November. It also has a high correlation with height, latitude, vegetation, temperature, and precipitation.

Yicun et al. (2020) in a study on severe and durable pollution in Tabriz City (East Azerbaijan Province) in northwest of Iran showed that when height of inversion layer decreases and gets closer to the ground, the amount of pollution also increases significantly. Atmospheric circulations, especially mid-level ridge of the atmosphere, are important in strengthening and sustaining pollution by creating dynamic suppression of the closed air. Khansalari et al. (2020) in a study on classifying synoptic patterns of air pollution in Tehran City in 2005 declared the high effect and role of synoptic conditions in middle of the troposphere, especially expansion of the ridge due to penetration of dynamic anticyclone systems on the region by creating a southern flow in development of intensity and extent of pollution. Many researchers have realized importance of AQI and have used it in their research including Ramezani et al. (2018) in a study on analysing the effect of climatic elements on air quality in Tehran City, Taghizadeh et al. (2019) in a research on AQI trend in Tehran City, and Gope et al. (2021) in a study on coronavirus disease 2019 (COVID- 19) in Venice (Italy). In fact, according to the AQI, air quality is divided into 6 categories, ranging from good to dangerous. Especially on days when the AQI level reaches dangerous threshold (301-500), people with heart and respiratory diseases should refrain from traveling in public places and outdoors. Also, the AQI assesses air quality considering average concentrations of 6 important pollutants, which has encouraged the authors to use it in this research, and to select only one pollutant, namely PM 2.5 and avoid investigating other pollutants.

\section{Study area}

Figure 1 shows map of geographical and physical location of Tehran City and the stations under study. Tehran City is located at the coordinates of $35.63^{\circ}-35.7^{\circ}$ of north and $51.29^{\circ}$ to $51.48^{\circ}$ of east. The number of stations recording air quality data for 6 pollutants reaches more than 22 stations, which can well monitor air quality situation by spatial distribution. As can be seen, value of height will gradually increase from southern half of Tehran City to northern part of it, and finally, a central ridge of Alborz is observed, which is like a barrier against the polluted air and increases concentration of pollutants on stable days of the atmosphere. 


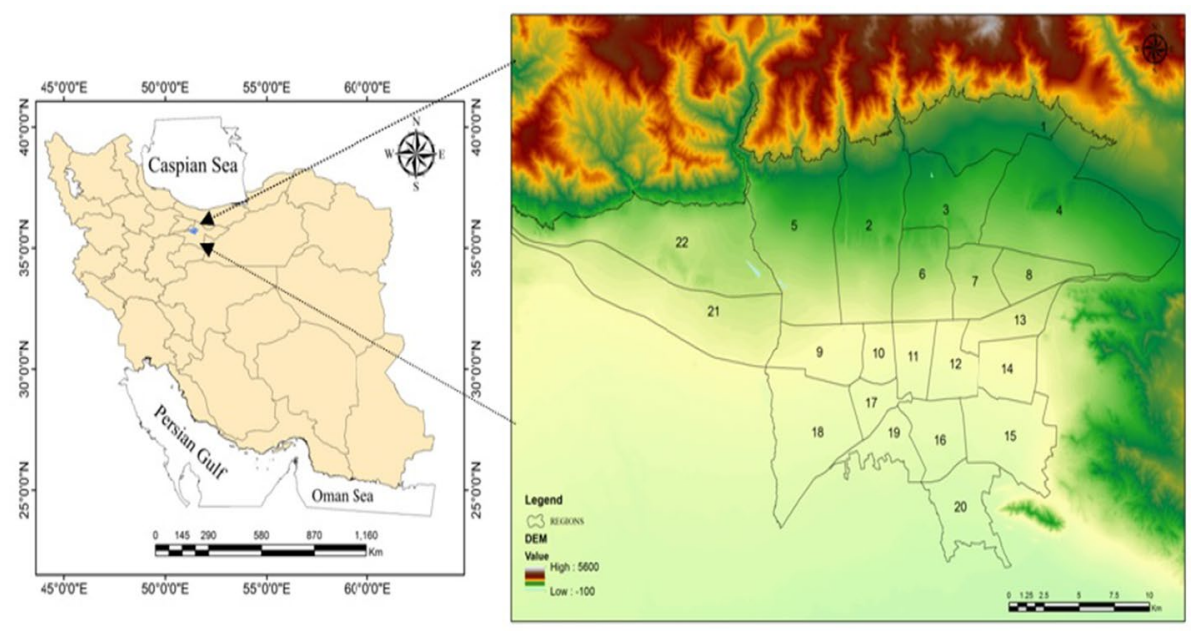

Fig. 1 The location of air pollution monitoring stations and height values in Tehran

\section{Data and methodology}

For conducting this research, firstly, daily data of AQI consisting of 6 indices $(\mathrm{CO}, \mathrm{O} 3$, NO2, SO2, PM 2.5, and PM 10) were obtained from Tehran Quality Control Company (www.airnow.tehran.ir) from establishment date of Tehrans' 22 stations on March 21, 2009 to December 30, 2019. According to Table 1, the polluted days with thresholds of 101 and more were selected based on AQI (U.S. environmental protection agency (USEPA 2014). Statistical analyses at different time scales were performed on the polluted days. For analysing atmospheric conditions and other indices, different events of most durable pollution wave (MDPW) and most durable clean wave (MDCW) during the mentioned period were studied to identify the MDPW in Tehran City during statistical period. Meteorological data were also obtained from the Meteorological Organization of Tehran in order to measure the correlation of the AQI between 4 stations of Mehrabad, Geophysics, Chitgar, and Aqdasiyeh. After identifying the MDPW and MDCW of Tehran City, for synoptic analysis of the network, data of the Center of Environmental and Atmospheric Studies (www.esrl.noaa. gov) with resolution of $2.5^{\circ}$ in latitude of $10^{\circ}-70^{\circ}$ of north and $10^{\circ}-90^{\circ}$ of east during occurrence of wave were obtained, from November 21, 2010 to January 2, 2011 and March 24 to April 4, 2019 for the MDPW and MDCW, respectively (Kalnay et al. 1996; Kistler

Table 1 Pollution threshold according to AQI index (USEPA 2014)

\begin{tabular}{lll}
\hline $\begin{array}{l}\text { Air qualiti index } \\
\text { (AQI) values }\end{array}$ & Levels of health concern & Colors \\
\hline $0-50$ & Good & Green \\
$51-100$ & Moderate & Yellow \\
$101-150$ & Unhealthy for sensitive groups & Orange \\
$151-200$ & Unhealthy & Red \\
$201-300$ & Very unhealthy & Purple \\
$301-500$ & Hazardous & Maroon \\
\hline
\end{tabular}


et al. 2001). Using the obtained data, mean maps, anomaly and atmospheric profiles of the sea level, geopotential height, omega, wind, humidity, temperature, and precipitation were plotted and interpreted in an appropriate level of grid analysis and display system (GrADS) software version 2.2.1. Temperature advection in the GrADS environment was calculated using Eq. (1) (Holton 2012). In this equation, temadv is temperature advection, and dtx and dty are also temperature evolvement in zonal and meridional direction, respectively.

Define Temadv $=-1 *((\mathrm{u} * \mathrm{dtx}) /(\cos (\mathrm{lat} * 3.1416 / 180) * \mathrm{dx})+\mathrm{v} *$ dty $/$ dy $) / 6.37 \mathrm{e} 6$

In the next step, for classifying synoptic patterns of the MDPW, the s-state cluster analysis method was applied using Euclidean distance and the Ward technique on the standardized geopotential height data at level of $500 \mathrm{hPa}$ (Eq. (2). Selecting the $500 \mathrm{hPa}$ as middle layers of troposphere to classify synoptic patterns is due to most of the atmospheric changes is occur in this level and the most mass of the atmosphere was in this level and overall this level can show better the atmospheric patterns (Alijani 2002). Also, Tierney et al. (2021) believe with increasing durability of positive geopotential height in $500 \mathrm{hPa}$ and consequently changing in unstable waves, temperature, emission of latent heat and also climatic extreme events have increased during recent years

$$
\left.e_{j k} \sqrt{\sum_{=1}^{n}\left(x_{i j-}\right.} x_{i k}\right)^{2}
$$

In the above equation, $e_{j k}$ represents the Euclidean distance, $X_{i j}$ is value of variable in the first point, $X_{i k}$ is circuit of the same parameter in the second point, which the distance between the two points is determined by obtaining their difference, and the distance matrices are formed by calculating the Euclidean distance for all points. Once this matrix is obtained, merge operation must be performed on its values. The Ward integration method (minimum variance) is commonly used in climatic studies (Kalkstein et al. 1987). The cluster analysis method has been used by many researchers in climatic studies including Bednorz and Tomczyk (2021), Cuell and Bonsal (2009), and Baltaci et al. (2020).

\subsection{Analysis instability indices}

For vertical survey of the atmosphere, determining the amount of instability indices, and different types of temperature inversion, climate database of the University of Wyoming (http://weather.uwyo.edu/upperair) was used for days with MDPW for Mehrabad station in Tehran City. After obtaining information about vertical atmosphere survey at Mehrabad station, more than 20 indices and profile information of atmospheric conditions for recognizing dynamic and thermodynamic status of atmosphere during days with severe pollution were drawn in RAOB software version 5.6. Temperature inversions were also determined and investigated by drawing a skew-T diagram for vertical section of the troposphere from 1000 to $100 \mathrm{hPa}$ per day of pollution wave (43 days) (Table 6). Examples of different inversions for pollution peak days are provided in Skew-T maps presented in Fig. 9.

\subsection{HYSPLIT model}

The hybrid single-particle Lagrangian integrated trajectory (HYSPLIT) model was first developed by the US Oceanic and Atmospheric Resource Laboratory in 1982 with assistance of the Australian Meteorological Office and is applied for tracking and 
predicting flow route of free pollutants as well as trajectory of air particles, volcanic ash, and fires caused by forest fires. The Lagrangian model of dust particle tracking is a complete system for calculating simple paths of air particles and their complex dispersions and simulations (Draxler et al. 2007). For determining trajectory of the pollutants and dust particles entering Tehran City, the Lagrangian model of dust particle tracking version 5 was used (Stein et al. 2015; Rolph et al. 2017), and particles were tracked at three height levels of 500,1,000, and 1,500 $\mathrm{m}$ above sea level and in time intervals of $48 \mathrm{~h}$ prior to occurrence of the selected peak days. For implementing the model, the total data from the US Atmospheric Forecasting Centre were used (ready. arl.noaa.gov/HYSPLIT). For the final analysis of operational data at global scale, data of atmospheric forecasting centre from the Global Data Integration System were used to provide primary input data to the system. Also, the Global Data Integration System collects observational data from all places around the world using telecommunications system and other resources continuously and uninterruptedly. Finally, the final atmospheric forecasting data are generated using a model similar to that used by the National Centre for Environmental Prediction to produce global forecasting system data (Stunder 1997).

\section{Results and discussion}

\subsection{Statistical analysis of Tehran city air pollution}

Different durations of pollution according to the AQI threshold of more than 100 during 2009-2019 showed (Fig. 2a) that the most type of MDPW was a one-day wave with 205 cases followed by the two-day wave with 65 cases, the 3-day wave with 38 cases, and other waves. The least durability was also observed ranging from 11-day to 43-day waves with each of them occurring once. Figure $2 b$ shows intensity of air quality according to the AQI on a daily scale and during statistical period. Although the AQI values show a very weak negative trend, especially since 2016 , occurrence of the polluted days is a dominant phenomenon throughout the year, especially in warm and cold seasons of Tehran City. The highest AQI value occurred on July 15, 2009 at intensity level of 381 and the least one occurred with intensity level of 30 in a few days since the first decade in April 2015. Figure $2 \mathrm{c}$ shows frequency regarding number of the polluted days per month during 2009-2019. The highest and lowest frequency was recorded in December, with 198 events and April with 47 events, respectively. Regarding analysis of frequency of the polluted days in each season (Fig. 2d), also autumn (October to December) with 422 days and spring with 232 days had the maximum and minimum frequency of the polluted days, respectively. The increase in pollutants' concentration and occurrence of the polluted days in warm and cold months of the year indicated a clear role of atmospheric currents in occurrence of this phenomenon. As shown in Fig. 2e, frequency of the polluted days per year also demonstrated a decreasing trend of this perilous phenomenon from 2014 onwards with the increasing trend of precipitation days (Fig. 2f) in Tehran City. The highest frequency of the polluted days was in 2011 with 221 days, and the least value was recorded in 2009 with 37 days. Despite a slight improvement in amount and frequency of precipitation days in the region and country in 2018-2019, the trend of precipitation has declined since 1998 (Darand and Pazhoh 2019a, b) that has continued along with severe and pervasive droughts 


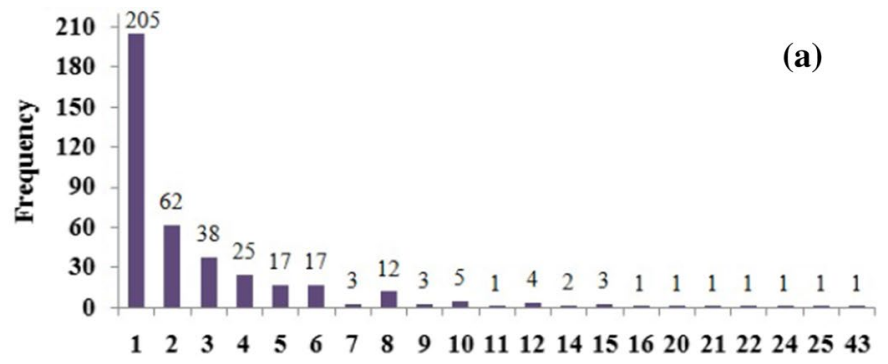

Durability
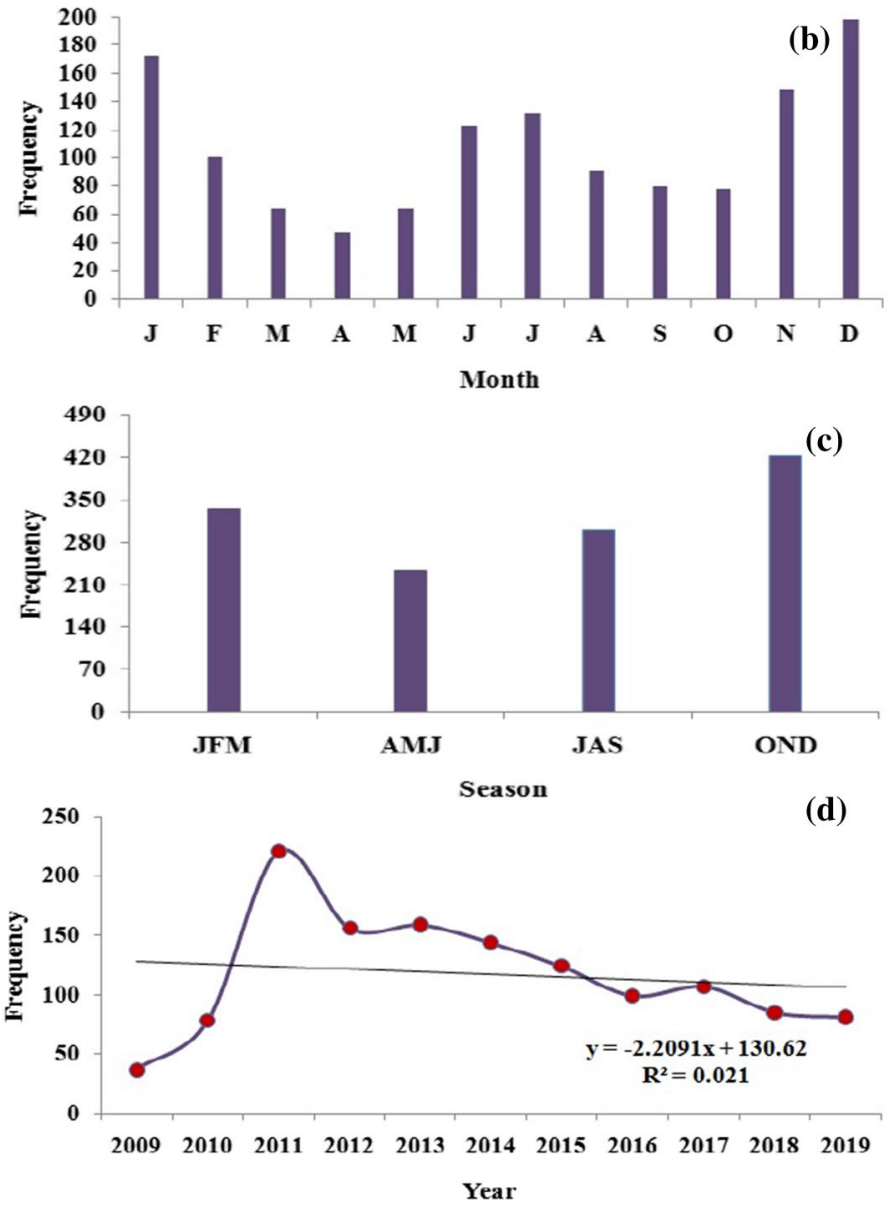

Fig. 2 a Different durations of the polluted days in Tehran City, b Frequency of the polluted days in each month, c Season, d Year, e Frequency of the polluted days (columns) and precipitation days (lines) in Tehran City during 2009-2019, f Severity of daily pollution according to the AQI

according to forecasting models of climate change of the country over the recent decades (Vaghefi et al. 2019; Mansouri-Daneshvar et al. 2019) and especially, Tehran metropolis as the most populous City, faces with different climatic and environmental hazards. 


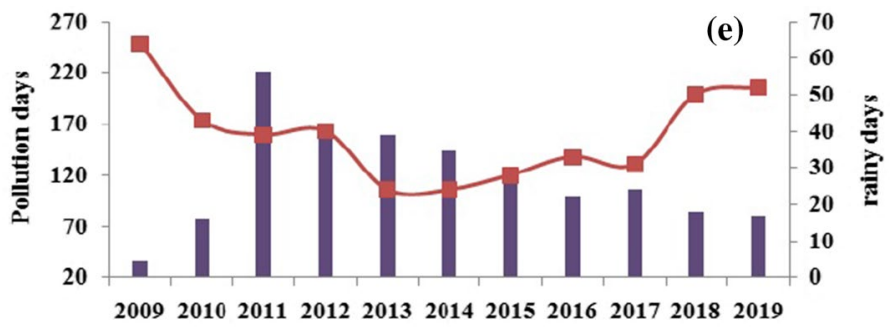

Year
- Pollution $\rightarrow$-Precipitation

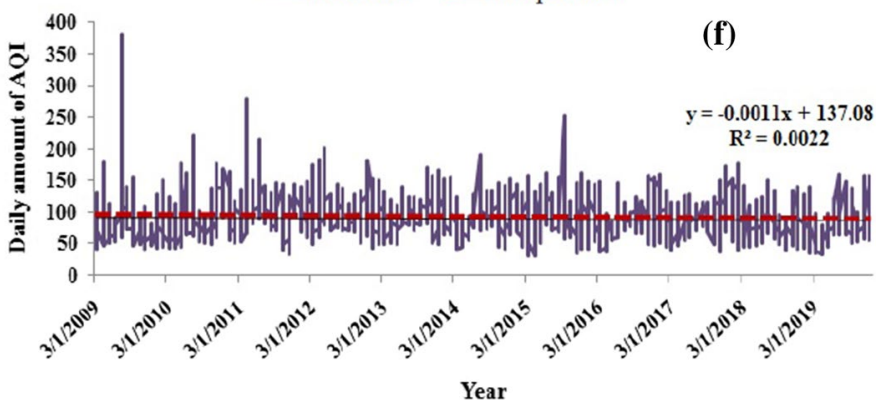

Fig. 2 (continued)

Figure 3 shows spatial distribution of mean AQI for 22 regions of Tehran City. As can be seen, the maximum pollution is in southwestern, western, and central regions of Tehran City, corresponding exactly to concentration of polluting industries in this part of the city

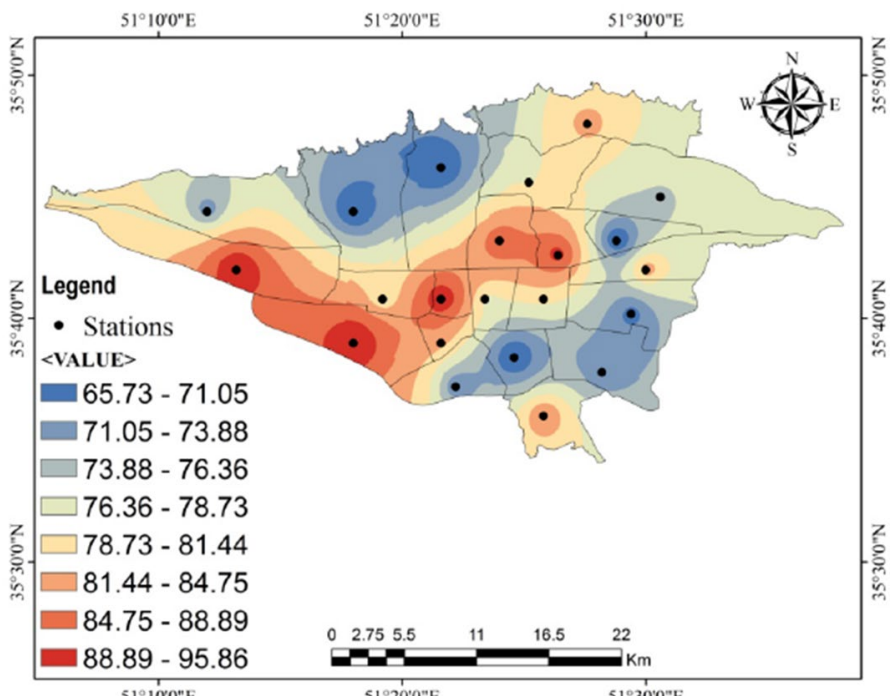

Fig. 3 Spatial distribution of average pollution according to AQI index of Tehran during the period 20092019 
and the polluted air currents of these industries is transmitted over the city due to frequent western and southern winds and with collision of this polluted air with mountains in north of the city, state of accumulation and suffocation prevails.

Figure 4 shows the MDPW in Tehran City during the whole period of analysis from 2009 to 2019. The wave began on November 21, 2010 and ended on January 2, 2011. In this wave, average AQI in all the studied stations was more than 100 (unhealthy for sensitive groups and those at higher risk) within 43 days, which is significant in its type.

Tables 2 and 3 show the relationship between AQI and atmospheric variables during the polluted $(A Q I \geq 101)$ and clean days $(A Q I \leq 50)$. In 4 meteorological stations and 4 pollution monitoring stations in vicinity and with a short distance from each other, respectively, including Mehrabad and Azadi, Geophysics and Villa, Aqdasiyeh and Tajrish, Chitgar and Pardisan, according to the following tables, there was a negative relationship between AQI with variables of mean and minimum temperature, relative

Fig. 4 Pollution intensity according to AQI in the MDPW (43 days) in Tehran City during 2009-2019

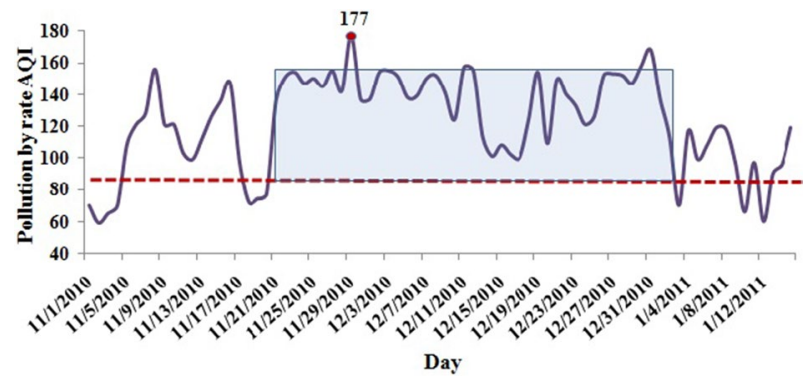

Table 2 Correlation coefficients of mean AQI with different variables in 4 selected stations Pollution and meteorology in Tehran during polluted days (AQI $\geq 100)$

\begin{tabular}{llllll}
\hline & Temp mean & Temp min & Temp max & R hum & Wind speed \\
\hline Mehrabad and Azadi & R: -0.391 & R: $-0.065^{* *}$ & R: $0.117^{* *}$ & R: -0.319 & R: $-0.221^{*}$ \\
& P: 0.1 & P: 0 & P: 0 & P: 0.09 & P: 0.03 \\
Geophysics and Vila & R: 0.259 & R: $-0.321^{* *}$ & R: $0.236^{* *}$ & R: -0.124 & R: $-0.334^{* *}$ \\
& P: 0.09 & P: 0.004 & P: 0 & P: 0.1 & P: 0 \\
Chitgar and Pardisan & R: $-0.319^{* *}$ & R: $-0.091^{* *}$ & R: $0.241^{* *}$ & R: $-0.347^{* *}$ & R: $-0.289^{* *}$ \\
& P: 0 & P: 0 & P: 0.006 & P: 0 & P: 0 \\
Aghdasiyeh and Tajrish & R: $-0.048^{*}$ & R: $-0.098^{* *}$ & R: $0.311^{*}$ & R: $-0.117^{*}$ & R: $-0.191^{* *}$ \\
& P: 0.03 & P: 0 & P: 0.02 & P: 0.05 & P: 0
\end{tabular}

Levels of significance: ${ }^{*} * p$-value $=0.01,{ }^{*} p$-value $=0.05$

Table 3 Correlation coefficients of mean AQI with different variables in 4 selected stations Pollution and meteorology in Tehran during clean days $(\mathrm{AQI} \leq 50)$

\begin{tabular}{llllll}
\hline & Temp mean & Temp min & Temp max & R hum & Wind speed \\
\hline Mehrabad and Azadi & R: $-0.037^{* *}$ & R: $-0.086^{* *}$ & R: 0.161 & R: -0.191 & R: $-0.289^{* *}$ \\
& P: 0 & P: 0.006 & P: 0.07 & P: 0.12 & P: 0 \\
Geophysics and Vila & R: $0.318^{* *}$ & R: $-0.343^{* *}$ & R: $0.219^{* *}$ & R: $-0.225^{*}$ & R: $-0.368^{* *}$ \\
& P: 0 & P: 0 & P: 0 & P: 0.05 & P: 0 \\
Chitgar and Pardisan & R: $-0.155^{* *}$ & R: $-0.245^{* *}$ & R: $0.271^{* *}$ & R: $-0.344^{*}$ & R: $-0.423^{* *}$ \\
& P: 0 & P: 0 & P: 0 & P: 0.04 & P: 0 \\
Aghdasiyeh and Tajrish & R: -0.027 & R: $-0.095^{* *}$ & R: $0.229^{* *}$ & R: $-0.173^{* *}$ & R: $-0.239^{*}$ \\
& P: 0.06 & P: 0 & P: 0 & P: 0 & P: 0.02 \\
\hline
\end{tabular}

Levels of significance: ${ }^{*} *$-value $=0.01,{ }^{*} p$-value $=0.05$ 
humidity, and wind speed and there was a positive relationship between AQI with maximum temperature. But, its significance with wind speed and minimum temperature was more than other parameters under study. Also, in Tehran City, meteorological parameters and AQI were more correlated in center (Geophysics and Villa stations) and west (Chitgar and Pardisan stations) of the city than other areas. Comparing two tables, it can be seen that the relationship between AQI with atmospheric variables was stronger during clean days than the polluted days, indicating involvement of other human factors (pollution caused by industry and transportation) in creating the suspended particles in the atmosphere, and atmospheric conditions actually increase intensity and durability of the polluted air in the city.

\subsection{Analysis of atmospheric conditions of the MDPW in Tehran City}

\subsubsection{Synoptic patterns classification of $500 \mathrm{hpa}$ of PMDW}

After applying cluster analysis with the Ward integration method on geopotential height data at the level of 500hpa, the polluted days of the MDPW in Tehran City and 3 synoptic patterns with different arrangements were identified (Fig. 5). According to (Fig. 6a) in the first model, the resulted ridge from subtropical anticyclone ridge extends all over Iran up to $65^{\circ}$ with northward direction in north of Russia when there is a strong orbital wind; while strong orbital winds prevail, there are no air suction conditions in middle levels. In these conditions, there is no or weak atmospheric turbulence. The highest average severity of pollution occurred (148.1) in the first pattern. As shown in (Fig. 6b), in the second synoptic pattern, like the first pattern, in addition to strong orbital winds at $500 \mathrm{hPa}$, the distance between co-height lines increases on Iran, and so calm (barotropic) conditions prevail quite slowly on these surfaces. In this case, despite penetration of the Baltic Lake from north of Europe and its location on the eastern Mediterranean; Iran completely experiences orbital airflow conditions. But in the third pattern, mostly seen during the last days of the MDPW (Fig. 6c) with westward direction of ridge resulting from subtropical anticyclone to the eastern Mediterranean, Tehran City is located behind low-depth penetrated trough from Central Asia. In this case, unlike other patterns, wind flow had a northwesterly direction and average pollution intensity reached by 142.1 with creation of continuous and extensive subsidence conditions (Table 4).

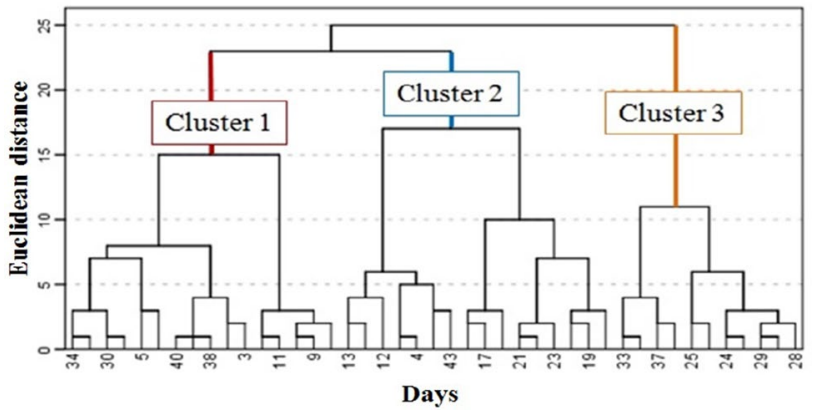

Fig. 5 Dendrogram of geopotential height data at $500 \mathrm{hPa}$ during 43-days of MDPW 

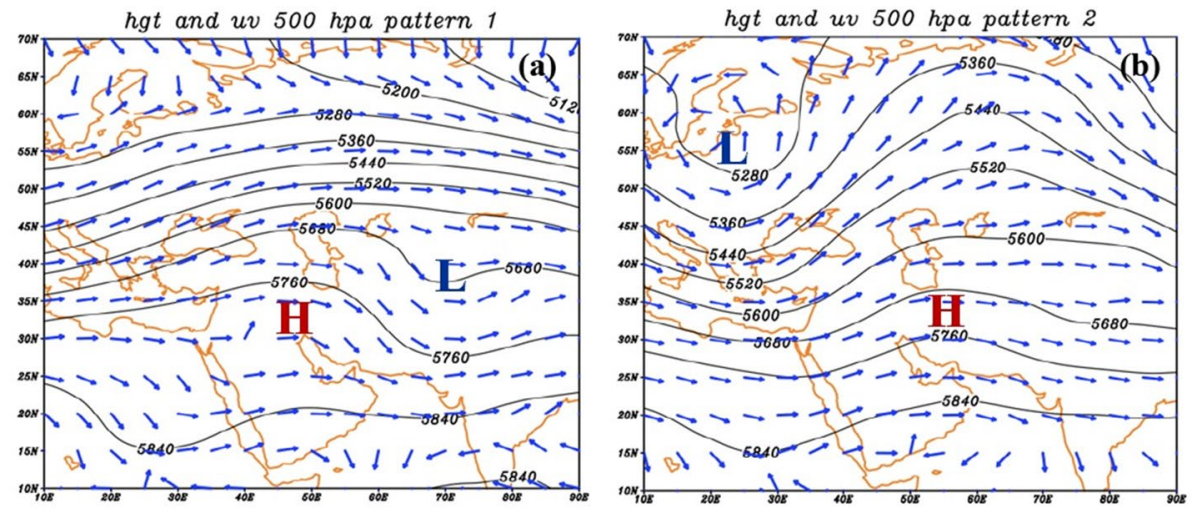

hgt and uv 500 hpa pattern 3

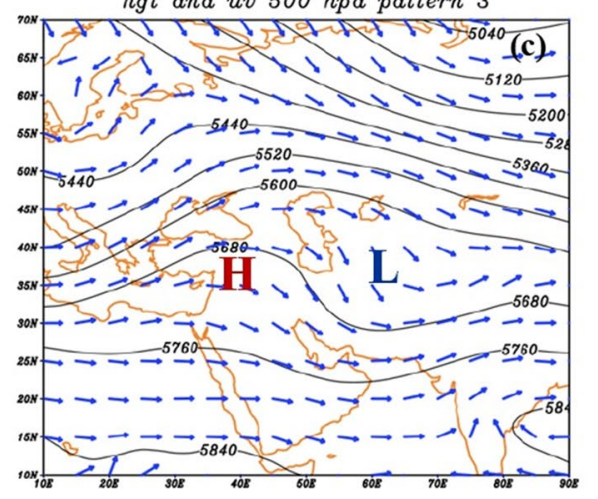

Fig. 6 Synoptic patterns of geopotential height of $500 \mathrm{hPa}$ (line) and wind vector (stream) of the MDPW Tehran, a first pattern, b second pattern, $\mathbf{c}$ third pattern

Table 4 Statistical characteristics of synoptic patterns of the MDPW in Tehran

\begin{tabular}{lllll}
\hline Synoptic pattern type & Cluster & Frequency & Pollution mean & $\begin{array}{c}\text { Occurrence } \\
\text { percentage }\end{array}$ \\
\hline Sub-tropical anticyclone ridge and orbital flows & $\mathrm{C} 1$ & 16 & 148.1 & 37.2 \\
$\begin{array}{l}\text { European low depth trough } \\
\text { Central Asia low depth trough/sub-tropical }\end{array}$ & $\mathrm{C} 2$ & 16 & 129.4 & 37.2 \\
$\quad$\begin{tabular}{l} 
anticyclone ridge \\
\hline
\end{tabular} & & 11 & 142.2 & 25.5 \\
\hline
\end{tabular}

\subsubsection{Synoptic analysis of MPDW of Tehran city}

Figure 7a shows mean status of sea-level pressure and sea-level wind vector during 43-day air pollution wave in Tehran City. According to (Fig. 7a), expansion of the Siberian highpressure with zonal intrusions and formation of the closed high-pressure cores from it on Iran resulted in a clockwise and gentle wind flow over the region's atmosphere. The main effect of the Siberian high-pressure on Iran is that it penetrates cold and dry air of Iran (Alijani 2007). Thus, when Iran is exposed to and penetrated by the Siberian high-pressure, the region shows a calm and polluted atmosphere. Along with steady state of the atmosphere at 

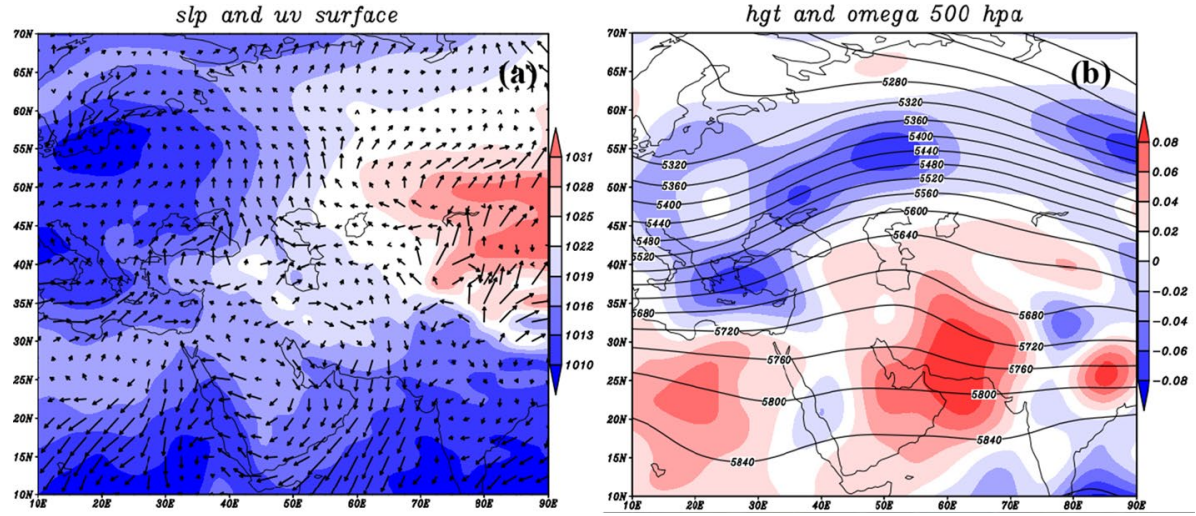

Fig. 7 Combination maps a Sea level pressure (color) and wind vector (stream), b Geopotential height (line) and omega (color) at $500 \mathrm{hPa}$ level of the MDPW for mean of 43 days

sea level, at $500 \mathrm{hPa}$, a huge ridge extends southward across the country to $65^{\circ}$ in north of Russia (Fig. 7b). With penetration of this ridge, the whole of the Middle East and country faced with the situation of positive omega (convergence and downfall of the air) and placement of descending and ridge of the atmosphere on the cold Siberian high-pressure on sea level added to stability and inactivity of the atmosphere and enhanced durability of the polluted wave (Cerrato-Alvarez et al. 2019). In this situation, the Mediterranean cyclonic systems in the west, in the Arabian regions in south of the earth's surface, and deep troughs of upper latitudes in middle atmospheric levels play a major role in occurrence of pervasive precipitation and atmospheric instability in Iran (Darand and Pazhoh 2019a, b). Thus, they are unable to penetrate the country and are diverted to northern and central Europe.

Warm temperature and anticyclone advection at 850 and $700 \mathrm{hPa}$ (Fig. 8) caused by penetration of a deep ridge from south latitudes or injection of warm and dry air of regions on Arabian Peninsula and Iraq and a decrease in atmospheric humidity to less than $3 \mathrm{~g} /$ $\mathrm{kg}$ caused strengthening of continuous stability and pollution in Tehran's atmosphere.
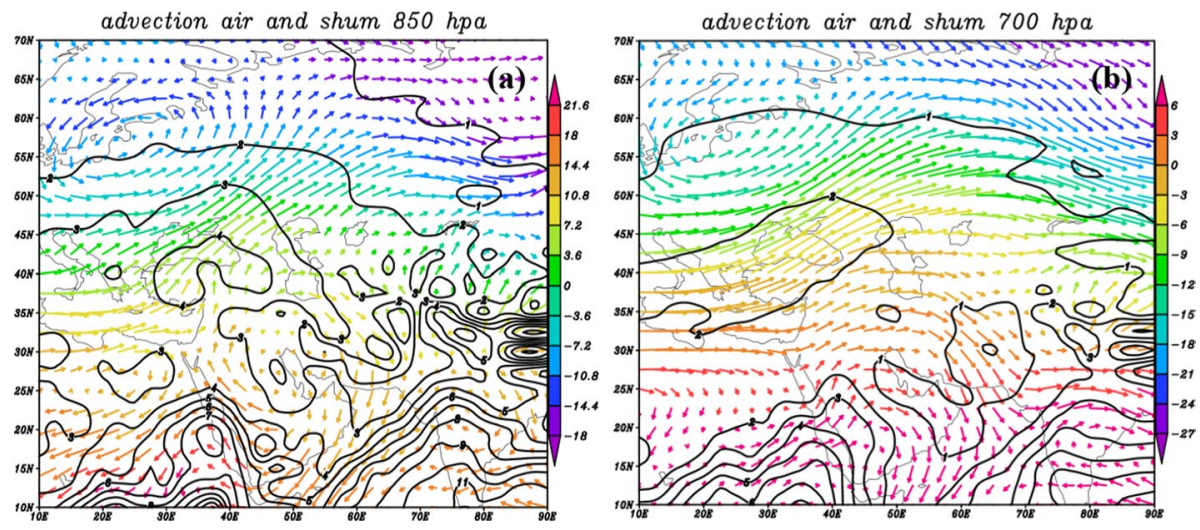

Fig. 8 Combination maps Temperature Advection (stream) and specific humidity (line), a $850 \mathrm{hPa}, \mathbf{b}$ $700 \mathrm{hPa}$ of the MDPW for mean of 43 days 
However, in dry and low precipitation years, such as 2010, the westward anticyclone circulation to $55^{\circ}$ in north and $30^{\circ}$ in east reduces precipitation and can cause climate hazards, particularly atmospheric pollution (Hejazizadeh et al. 2019).

An analysis of meridian pressure profile (Fig. 9a) during the MDPW on Tehran City identified unique conditions of high-pressure systems, particularly the Siberian. These conditions lead to a descending and convergent flow, in line with the anticyclone of the middle atmosphere, on Tehran City, resulting in accumulation of pollutant particles and an increase in permissible level of pollution. It is important to note that intensity of high pressure in middle of the wave from 11 to 13 December was weakened in line with the reduction of atmospheric pressure, and the AQI situation reached by 91 on December 13, 2010. However, these conditions were temporary, and the AQI again was increased to 127 on December 14. On most of the polluted days of the MDPW, a descending but slow flow was active on the atmosphere of Tehran City (Fig. 9b) where the amount of atmospheric humidity reached its lowest level. On the days with the highest levels of pollution, the atmosphere was more stable such that the minimum humidity levels were consistent with the full descending air package. Yet, from December 11 to 13, when the AQI reached its lowest level, the humidity and air flow were increased.

Figure 10 shows an increase in temperature intensity profile of Tehran City during the MDPW starting on November 21, 2010. Thus, on peak days of the wave November 29 and 30 , intensity of pollution at temperatures more than $20^{\circ} \mathrm{C}$ reached by $800 \mathrm{hPa}$. The highest temperatures extended beyond $0^{\circ} \mathrm{C}$ and continued up to $600 \mathrm{hPa}$. In the second half of the AQI, no other long wave of temperatures above $20^{\circ} \mathrm{C}$ was seen. Negative temperatures were also seen from above 600 to about $800 \mathrm{hPa}$. Intensity of each of the investigated elements corresponded precisely with fluctuations in pollution intensity on Tehran City.

Figure 11a shows ratio of sea level pressure anomaly to 30-year average (1981-2010). As can be seen, the maximum positive anomaly corresponded to high-pressure system $65^{\circ}$ in north of Russia crossing the Baikal and Caspian lakes as penetrating southern regions of Saudi Arabia. Rate of increase in long-term positive anomalies in the Middle East and country is more than $1 \mathrm{hPa}$. The $1 \mathrm{hPa}$ increase is consistent with the existence of a cold core high-pressure system caused by the Siberian multi-core system over Iran and the region. As shown in (Fig. 11a), the minimum negative pressure anomaly is located in
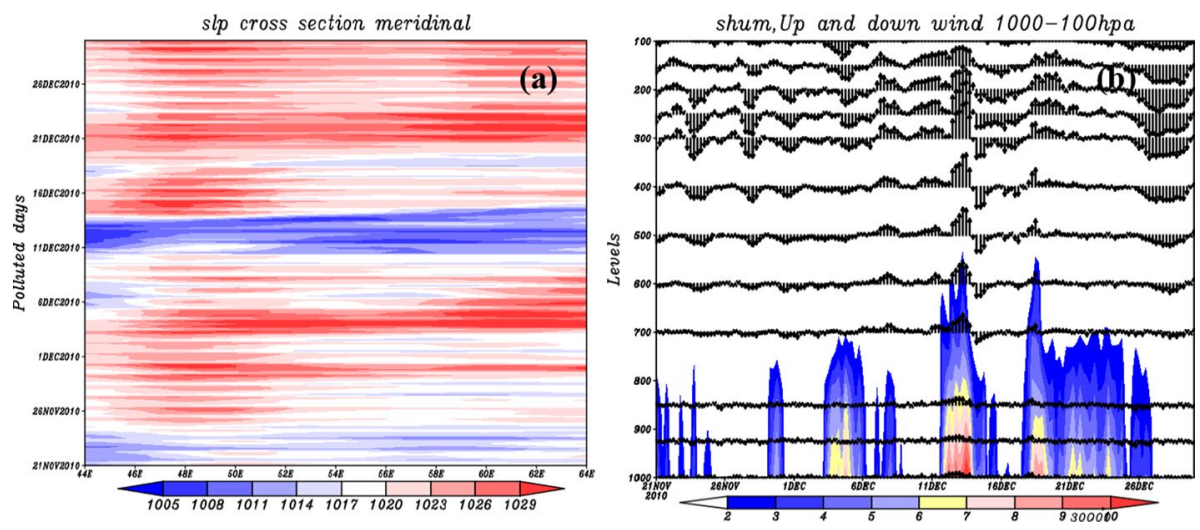

Fig. 9 Combined maps a mean of meridional pressure profile on the atmosphere of Tehran, b Shum profile, Upward and downward wind profile from 1000 to $100 \mathrm{hPa}$ level, November 21, 2010 to January 2, 2011 of the MDPW 
Fig. 10 Air temperature profile of Tehran from 1000 to $100 \mathrm{hPa}$ level, November 21, 2010 to January 2, 2011 during the MDPW
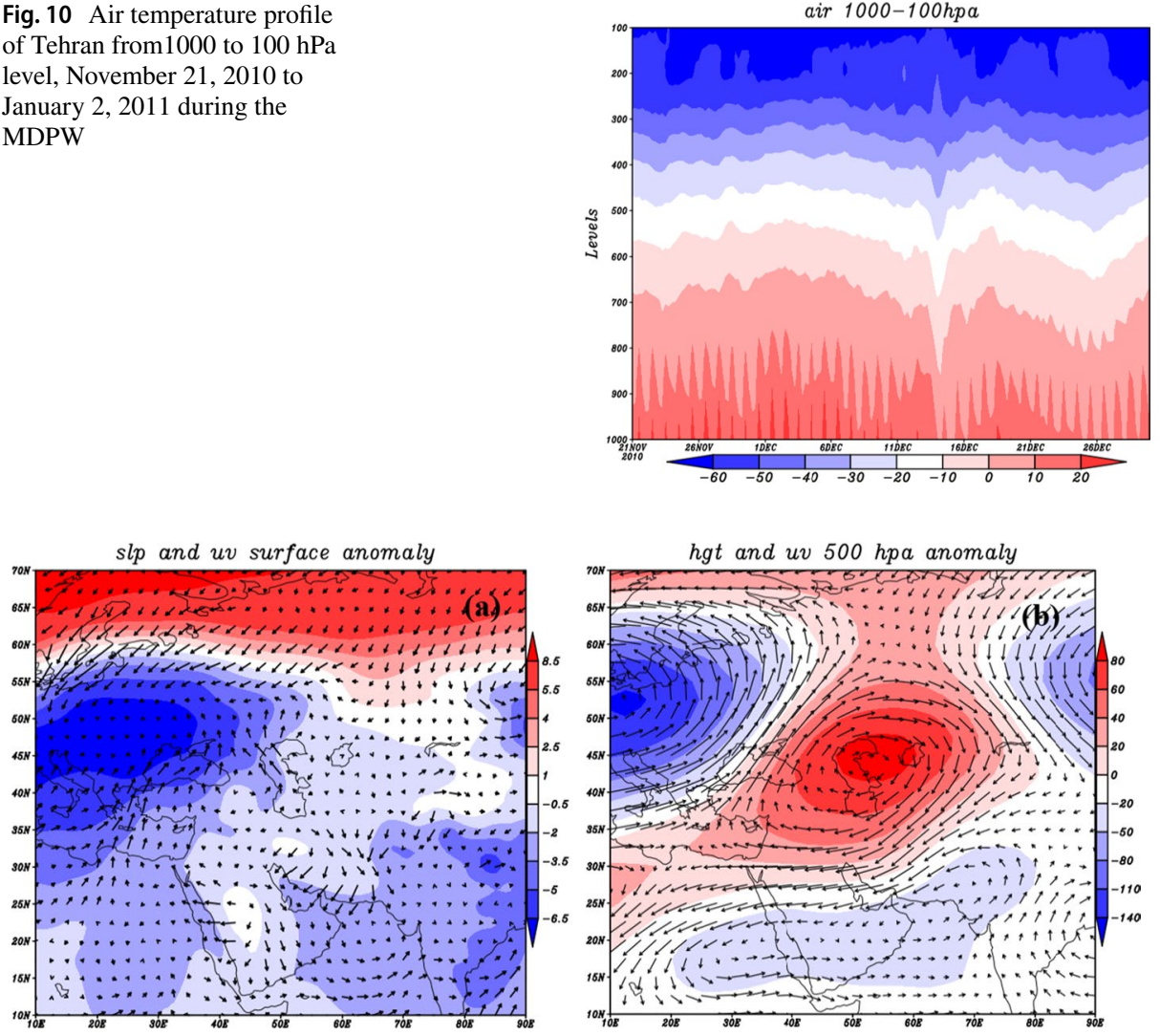

Fig. 11 Combination maps a Sea level pressure (color) and wind vector (stream) b Geopotential height (shaded) and wind vector (stream) anomaly at $500 \mathrm{hPa}$ level, during mean of 43 days for the MDPW Compared to the long term 1981-2010

central and southern Europe, extending from the meridian to northern regions of Europe. The geopotential height anomaly of $500 \mathrm{hPa}$ (Fig. 11b) is also aligned with sea level pressure anomaly such that the country and study region are influenced by positive anomalies of geopotential height penetrated from Northern Russia and Northern Africa. The maximum positively increased anomaly compared to long-term geopotential anomaly is located between the Baikal and Caspian lakes within $80 \mathrm{~m}$ of geopotential height. The greatest increase in this positive anomaly in northern half of Iran ranges from 40 to 60 geopotential $\mathrm{m}$, indicating an increase in anticyclone circulations and huge mid-level ridges over Iran causing the increased stability and convergence of currents (Fiddes et al. 2016) during the MDPW in Tehran City. It was also shown that regions of the Middle East and high latitude of $60^{\circ}$ both had positive anomalies and were similar to each other, and settlement and occurrence of widespread negative anomalies on the European continent and in Central and East Asia are also similar as these conditions show how the complex relationship between different elements and factors influences the climate.

Mid-level omega anomaly values indicate conditions, such as geopotential height and sea-level pressure. As shown in Fig. 12a, the Middle East and the whole of Iran have high positive omega values, confirming formation of descending and converging currents over 

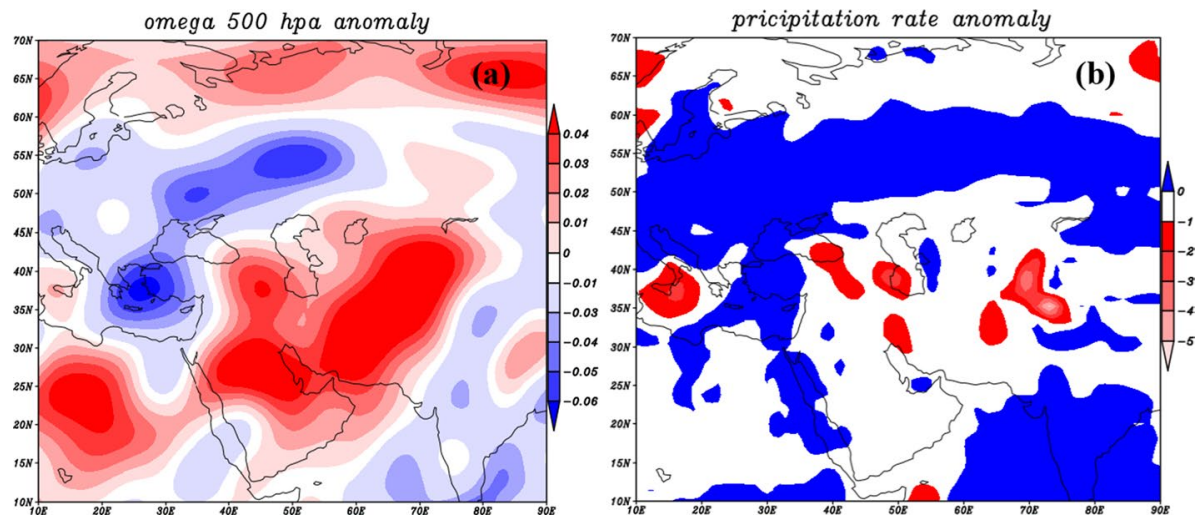

Fig. 12 a Omega anomaly at $500 \mathrm{hPa}$ level, b Pricipitation rate anomaly during mean of 43 days for the MDPW compared to the long term 1981-2010

the region. The positive omega-level increase in long-term was about 0.04 Pascal per second on Tehran's atmosphere.

Lack of divergence of flow within dominant air packages over the region provides the conditions for reduction of wind speed and spatial concentration, prevents outflow of the polluted air in Tehran metropolis, and adds to durability of pollution. In precipitation anomaly (Fig. 12b), like the other maps of the studied anomalies in the Middle East region particularly Iran, a decreasing trend of stability and precipitation is observed. The extent of the regions associated with negative precipitation anomalies indicates the role of largescale synoptic patterns in changing rainfall and occurrence of pervasive, severe, and durable waves of pollution and other hazards in the region (Zhou et al. 2018).

\subsection{Analysis of instability indices of durable wave of the polluted days}

At this stage, status of instability indices for days with the longest-duration of pollution waves in Tehran City was investigated between 2009 and 2019. Using the results presented in Table 5, type and frequency of temperature inversions; frequency of different wind

Table 5 Type and frequency of temperature inversions, frequency of different wind directions and days with cloudiness at levels of 1000 to $100 \mathrm{hPa}$ troposphere during 43 days for the MDPW

\begin{tabular}{|c|c|c|}
\hline $\begin{array}{l}\text { Frequency of cloudy days in tropo- } \\
\text { sphere }\end{array}$ & $\begin{array}{l}\text { Days frequency of different wind } \\
\text { directions }\end{array}$ & $\begin{array}{l}\text { The type and frequency } \\
\text { of days with temperature } \\
\text { inversion }\end{array}$ \\
\hline No clouds: 26 & Western: 14 & Front: 2 \\
\hline Cloudy on levels 1000 to $700: 3$ & Southwest: 6 & Radiant: 6 \\
\hline Cloudy on levels 700 to $500: 8$ & Southern: 3 & Subsidence: 16 \\
\hline \multirow[t]{3}{*}{ Cloudy on levels 500 to $300: 6$} & Southwest-west: 8 & Subsidence-radiant: 10 \\
\hline & West-Northwest: 3 & Subsidence-front: 2 \\
\hline & $\begin{array}{l}\text { Oscillating wind from south to north- } \\
\text { west: } 8\end{array}$ & Non subsidence: 7 \\
\hline
\end{tabular}


directions; and days associated with cloudiness across different troposphere levels were analysed. During 43 days, (which correlated with the days of the longest duration of pollution), five types of inversion were identified, most of which included 16 cases of subsidence. At least, two cases of frontal type were observed. Temperature inversion in relation to type of subsidence and radiation subsidence played the most significant role in creating a stable atmosphere (Tavousi and Hossein-Abadi 2017), confirming that trans-regional synoptic systems, such as the Siberian system in the east and subtropical anticyclone in the west play a role in creating and reinforcing risky phenomena. On all the studied days, wind direction from sea surface to upper levels of the troposphere varied from south to northwest, most frequently in the form of westerly wind in Tehran's atmosphere profile. Frequency of cloudy days in the troposphere also showed a correlation between the polluted days and those with the fewest clouds. On other days, cloudiness was observed in a small part of the troposphere, meaning that the cloudiest days were at levels above $500 \mathrm{hPa}$ and with a thin thickness of about $100-200 \mathrm{hPa}$.

Table 6 shows frequency of the polluted days in terms of severity of each of instability indices during the pollution wave, through classification by display model of upper atmosphere status. In the context of the studied indices, instability levels were low on most days when there was a pollution wave. The wind speed index in upper, middle, and lower troposphere levels was also weak on most of these days. The index of cross totals (CT) was equal to $850 \mathrm{mb}$ dewpoint minus the $500 \mathrm{mb}$ temperature showing a poor level on most of the days. In other words, with the increase in temperature and dewpoint, air flow in Tehran City was at a stable level. The Jefferson Index indicating the probability of a thunderstorm inside air flow was poor for more than 23 days during pollution wave. The $\mathrm{K}$ index indicates status of vertical motions and humidity inside the air package in terms of temperature and dewpoint differences, which varied between 850 and $500 \mathrm{hPa}$, whereas the Ko index that indicates states of vertical motion atmospheres based on dynamic forces of $500 \mathrm{hP}$ and other important indices showing stability and instability of the atmosphere, such as the Showalter index (SI) that is a measure of thunderstorm potential and severity, the severe weather threat index (SWEAT), convective available potential energy (CAPE) index, the thunderstorm potential index (Thompson index), vorticity level in air mass index by storm relative helicity (SREH), level of free convection (LFC), and lifted index were at weak levels on most of the days.

Figure 13 demonstrates an example of a Skew-T diagram for the most severe days during the pollution waves in Tehran City. As shown in Fig. 13, westerly and south-westerly wind directions, temperature and drought inversions, and atmospheric stability are dominant features of the polluted days in Tehran City.

\subsection{Backward trajectory of peak days of air pollution in Tehran City}

Analysing air trajectory stream including the polluted particles and dust during peak days of the MDPW by HY SPLIT models showed that dry regions of far areas, such as deserts of southern Iraq and dry pits of Central Iran were involved in generation of dust particles (Fig. 14). Simultaneously, pollutant particles produced by industry as well as light and heavy vehicles in Tehran City also reduced air quality and caused emergence of durable pollution wave. In fact, in most of the study days, trajectory route of particle entrance was formed by an anticyclone that corresponded to a huge ridge caused by a penetrating subtropical anticyclone system that led to transition of flow from dry adjacent areas to parts of 
Table 6 Frequency of polluted days in terms of severity of each instability indices during a durable wave based on the classification of the upper atmosphere conditions of RAOB model during mean of 43 days for the MDPW

\begin{tabular}{|c|c|c|c|c|}
\hline Row & Parameter & Weak & Moderate & Strong \\
\hline 1 & $200 \mathrm{mb}$ wind Speed $(\mathrm{kt})$ & 28 & 11 & 2 \\
\hline 2 & $500 \mathrm{mb}$ wind Speed $(\mathrm{kt})$ & 36 & 4 & 3 \\
\hline 3 & $850 \mathrm{mb}$ wind Speed $(\mathrm{kt})$ & 41 & 1 & \\
\hline 4 & $1850 \mathrm{mb}$ Dewpoint $(\mathrm{C})$ & 42 & & \\
\hline 5 & $700-500 \mathrm{mb}$ lapse rate $(\mathrm{C} / \mathrm{km})$ & 41 & & \\
\hline 8 & CAPE Total & 1 & & \\
\hline 9 & LFC-LCL height (m) & 1 & & \\
\hline 10 & LFC_Level of Free Convection (mb) & 1 & & \\
\hline 11 & LI—Lifted Index & 1 & & \\
\hline 12 & CT—Cross Totals & 41 & 1 & \\
\hline 13 & JI—Jefferson Index & 23 & 12 & 1 \\
\hline 14 & K Index & 35 & 1 & \\
\hline 15 & KO Index & 24 & 8 & 2 \\
\hline 16 & LI-Lifted Index & 43 & & \\
\hline 17 & S Index & 35 & 1 & \\
\hline 18 & SI-Showalter Index & 40 & & \\
\hline 19 & srH—storm-relative Helicity $(0-3 \mathrm{~km})$ & 35 & 6 & \\
\hline 20 & Surface Dewpoint (C) & 39 & & \\
\hline 21 & SWEAT Index & 40 & & \\
\hline 22 & T1/T2 Gust (kt) & 20 & 8 & \\
\hline 23 & TI-Thompson Index & 39 & & \\
\hline 24 & TQ Index & 42 & & \\
\hline 25 & TT-Total Totals & 37 & 1 & \\
\hline 26 & VT_-Vertical Totals & & 15 & 25 \\
\hline 27 & WBZ—WetBulb Zero Hgt (ft,AGL) & 38 & & \\
\hline 28 & Windex (kt) & 12 & 5 & \\
\hline
\end{tabular}

Iran like Tehran City (Ashrafi et al. 2014; Arkian and Nicholson 2018; Ranjbar-Saadatabadi and Azizi 2012).

\subsection{Analysis of atmospheric conditions during the MDCW in Tehran City}

Investigation of the MDCW that happened between 2009 and 2019 showed that in fact, this 12-day period (March 24 to April 4, 2019) had the highest durability during the whole statistical period with an AQI less than 50 (classified into the category of clean and healthy air, Table 1) in Tehran City. There were days with an AQI of less than 50 in the other years under study, but like the mentioned period in 2019, they did not have this durability and continuity and were seen more sporadically. This period coincided with occurrence of heavy and pervasive precipitation in different regions of Iran including Tehran Province (Fig. 16c), which caused flooding and casualties in western, southwestern, and northern regions of the country (Moradi and Ranjbar-SaadatAbadi 2019). The atmosphere 

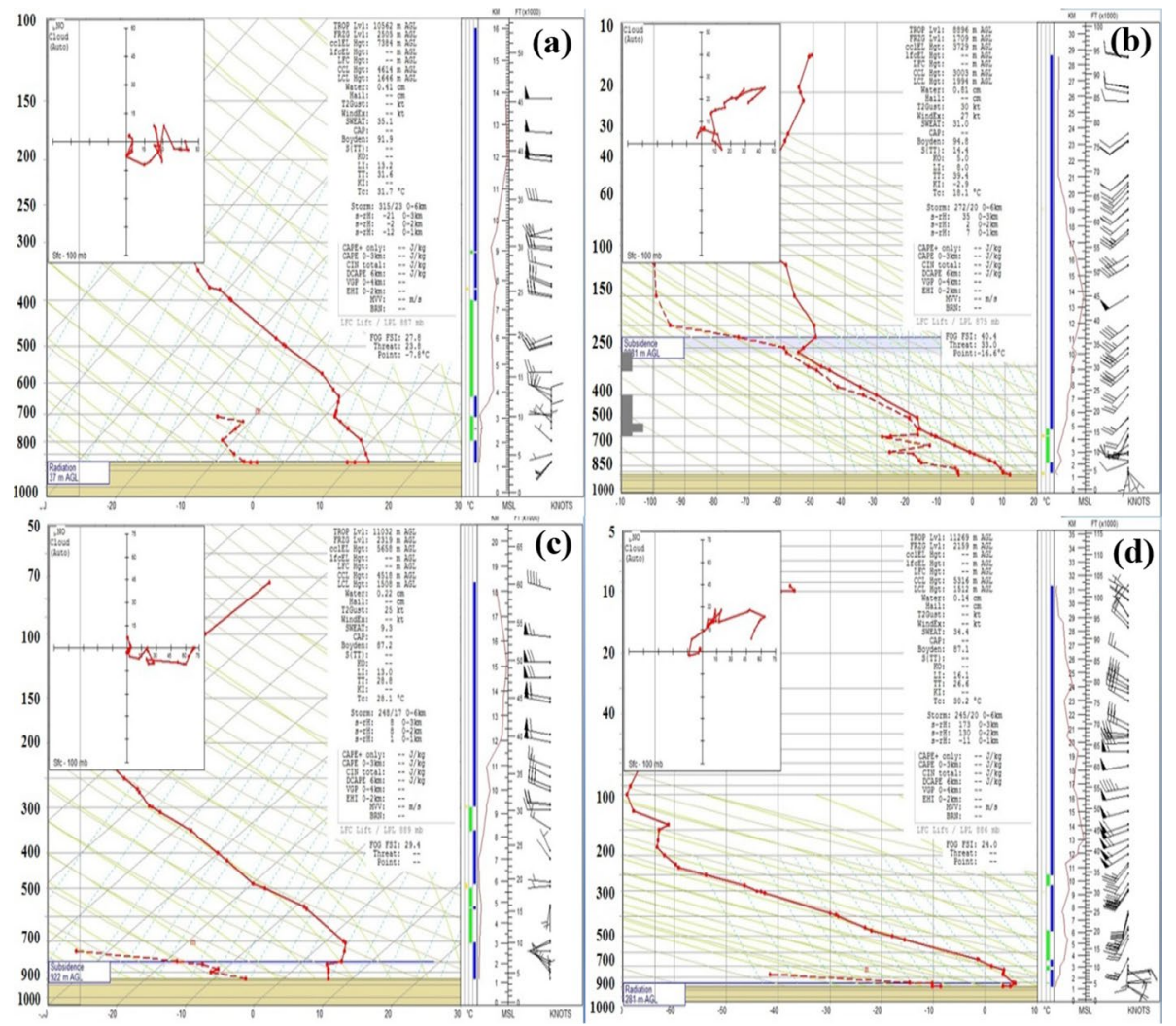

Fig. 13 Example of skew-T diagram in the peak of the pollution days a 29 Nov 2010, b 11 Dec 2010, c 30 Dec 2010, d 31 Dec 2010

condition can be used to describe the situations led to the cleanest period in Tehran City. For avoiding overrepresentation in paper, only mean and anomalies levels were presented for sea level pressure (Fig. 15a), maps and a geopotential height of $500 \mathrm{hPa}$. According to mean geopotential height map of $500 \mathrm{hPa}$ (Fig. 15b), penetration of a deep and widespread trough from north of Russia to Eastern Africa, and location of the country and Tehran City in eastern half and at front of the trough, caused a divergence in warm and humid southern airflow and created an unstable atmosphere. During this period, center of the anticyclone laid to west of the Arabian Sea, playing an important role in creation of heavy rainfall and decreasing pollution levels in the country by injecting warm and humid air into the trough.

In sea level pressure map of sea surface, multi-core low-pressure system on the Arabian Peninsula, the Eastern Mediterranean, and Central Iran formed an inverted trough along mid-level trough causing advection of humid air flow of southern water sources into the country through a cyclonic circulation. These conditions are precisely contrary to occurrence of pollution wave so that widespread low-pressure conditions were developed from northern regions of 60-degree latitude in north of Russia to Southern Arabian Peninsula continuously and the Azores tropical high-pressure was seen on Europe. This cold highpressure air from Europe injected cold air back into low-pressure air of the Middle East via collision with warm air inside low-pressure area, causing severe pressure gradients and 
NOAA HYSPLIT MODEL Gories ending at 1200 UTC 29 Nov 10 GHDA Meteorological Data

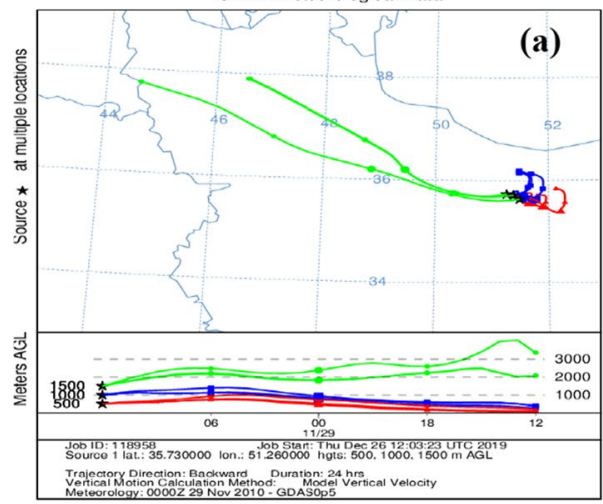

NOAA HYSPLIT MODEL

Backward trajectories ending at 1200 UTC 30 Dec 10

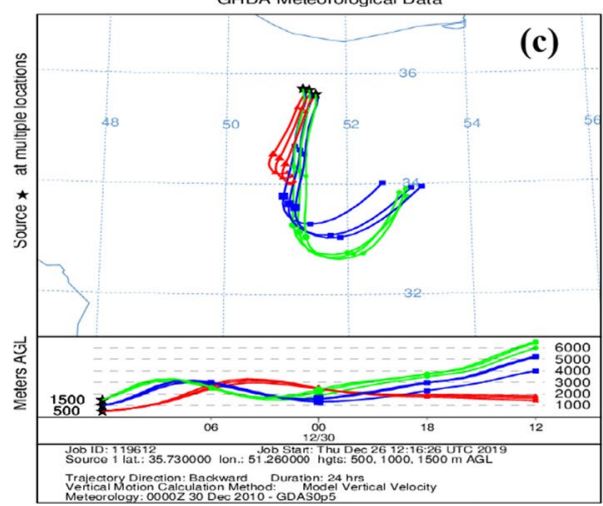

NOAA HYSPLIT MODEL NOries ending at 1200 UTC 11 Dec 10 GHDA Meteorological Data

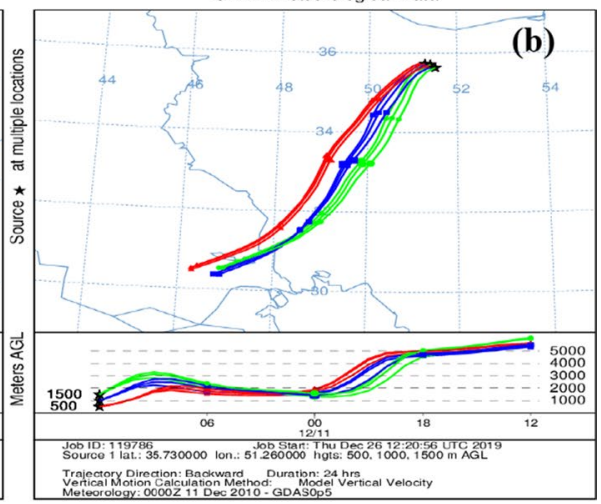

NOAA HYSPLIT MODEL

Backward trajectories ending at 1200 UTC 31 Dec 10 GHDA Meteorological Data

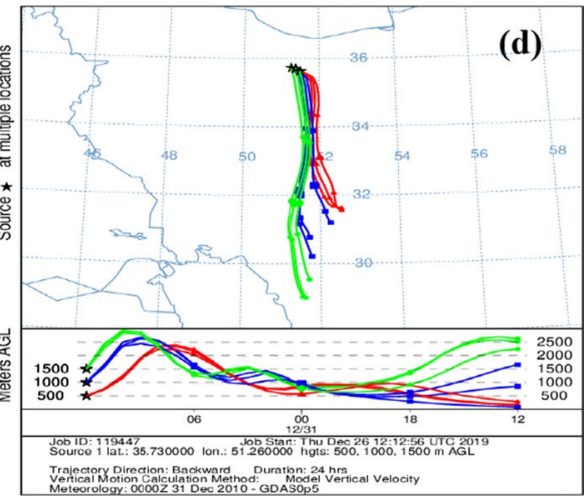

Fig. 14 Trajectory backward of pollutant particles and dusty during the peak days of the durable wave in Tehran, a 29 Nov 2010, b 11 Dec 2010, c 30 Dec 2010, d 31 Dec 2010

slp and uv surface

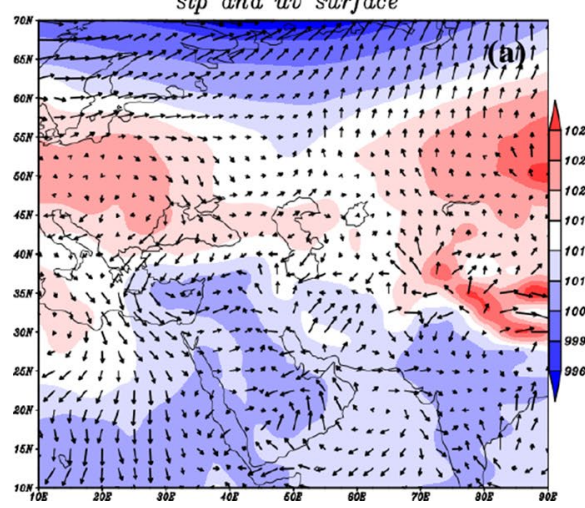

hgt and uv 500 hpa

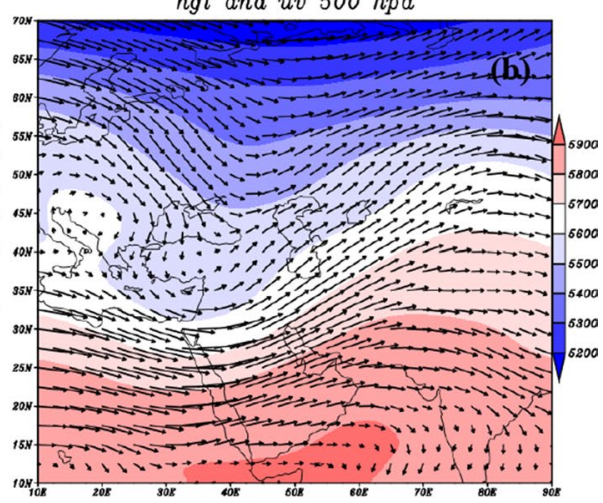

Fig. 15 Combination maps a Sea level pressure (color) and wind vector (stream), b Geopotential height (color) and wind vector (stream) at the level of $500 \mathrm{hPa}$ of the MDCW in Tehran for the mean of March 24 to April 4, 2019 
strong instability during durable clean-air period (Fig. 16a). The reduced anomaly at the geopotential height of $500 \mathrm{hPa}$ in the Middle East exceeded 80 geopotential m (Fig. 16b) and was higher than $5 \mathrm{hPa}$ in the sea-level pressure map (Fig. 16a) in long-term (30-year period spanning 1981-2011). The extended path of this negative height and pressure anomaly exactly coincided with mean maps, indicating successive penetration of deep troughs and occurrence of atmospheric instabilities in March and April 2019 in Iran and the study region.

\section{Conclusions}

In the present study, synoptic analysis was done on instability indices and sources and routes of entry of the polluted air in Tehran City were traced, and also, conditions regarding occurrence of the MDCW and MDPW were compared. Results of the study showed that the highest air pollution durability occurred during 2009-2019 over 43 days, from November 21, 2010 to January 2, 2011. The statistical period was divided into two periods before 2012 and after it so that before 2012, frequency of the polluted days was increasing,
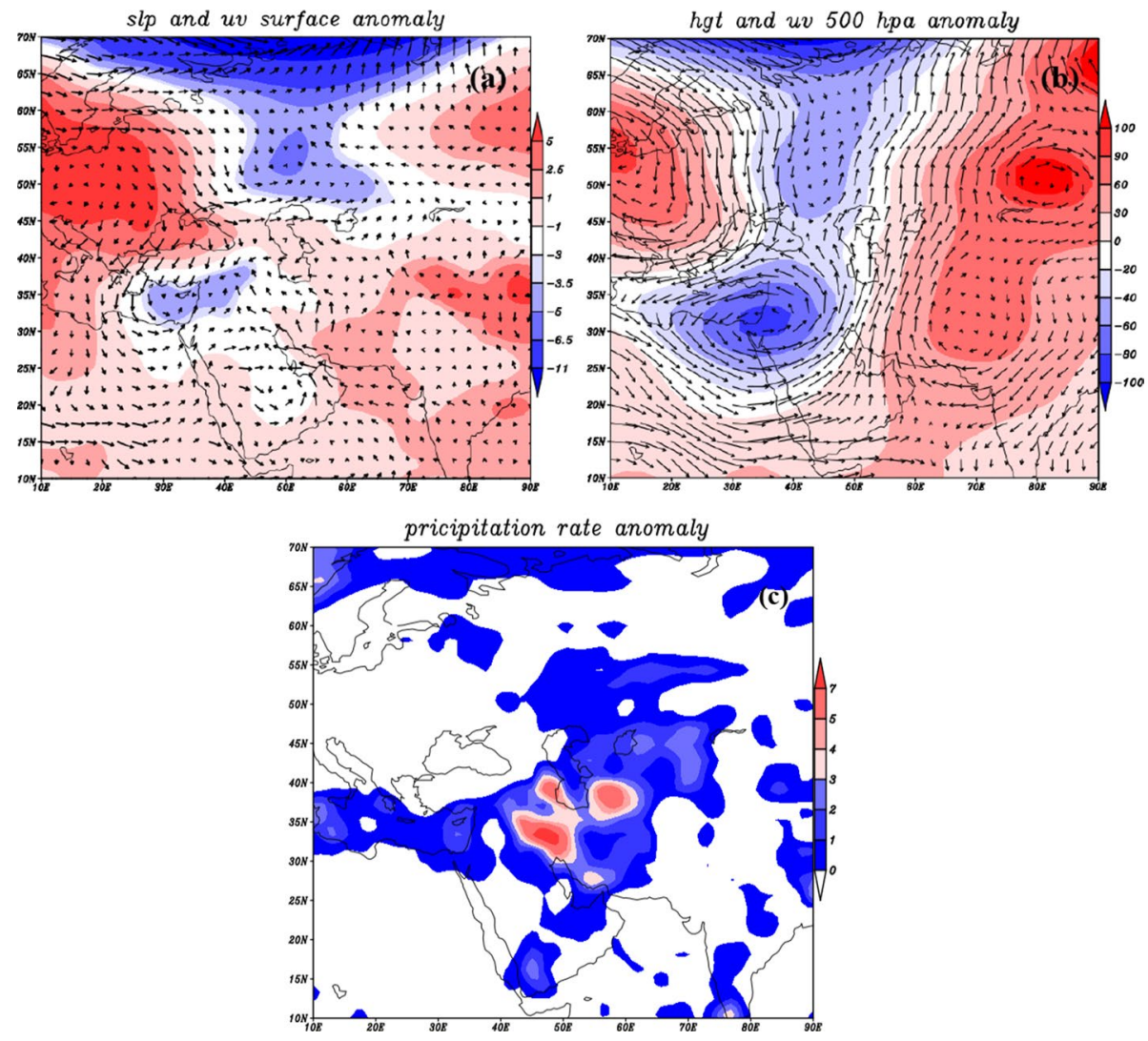

Fig. 16 a SLP and wind vector sea surface anomaly, b Geopotential height and wind vector and $500 \mathrm{hPa}$ anomaly, c Pricipitation rate anomaly, mean of March 24 to April 4, 2019 compared to the long-term period 2010-1981 
which is consistent with the results obtained in the research by Saniei et al. (2016), and after 2012, frequency of the polluted days was gradually decreased and precipitation days were increased, thus precipitation played a positive role in reducing pollution in Tehran City. The highest pollution frequency was observed in December, and the lowest pollution frequency was found in April. At seasonal scale, autumn and spring showed the highest and lowest frequencies of the polluted days, respectively. The maximum air pollution levels in the southwest and west of Tehran City corresponded to concentration of pollutants emitted by industries and the main route of entry of systems into Tehran City from western provinces of the country, respectively. During the longest air pollution period in Tehran City (43 days), average AQI of all stations exceeded 100, indicating unhealthy conditions for sensitive groups, and AQI was gradually decreased and weakened since mid-wave, December 12. However, the pollution period with high fluctuations persisted until January 2, 2011. For investigating the role of atmospheric circulation, first 3 patterns creating MDPW were identified by applying cluster analysis with Ward integration method on the network data of the geopotential height of $500 \mathrm{hPa}$. Analysis of these patterns showed that there are many similarities in terms of their position and arrangement. Such that penetration of subtropical high-pressure tabs from southern latitudes on Iran and the study area played a significant role in creating a stable climate and durable pollution by creating convergence, subsidence, and accumulation of air flow in the sea level.

Synoptic analysis also showed that during the observed long-term pollution period, penetration of the cold Siberian high-pressure from eastern part of the country (Karami et al. 2017) and its extension to southern parts of Saudi Arabia caused circulation of anticyclonic air in Tehran City, with dominant directions from southwest and west of the country. Along with these conditions, extension of a huge ridge across the country to north of Russia in middle levels of atmosphere caused a declining and converging atmosphere. As a result, humidity was decreased and temperature was increased. Accordingly, pressure and height anomalies at the level of $500 \mathrm{hPa}$ were also positive and increased during Tehran's longest pollution period (over 30 years, from 1981 to 2011). Intensity of positive geopotential height anomaly was much higher than sea-level pressure, indicating more important role of upper levels in creating a descending and calm atmosphere, resulting in pollution at the sea level (Mashat and Awad 2016). Moreover, precipitation anomalies were also negative across the country and region under study, confirming the role of large-scale synoptic patterns in changing precipitation conditions and occurrence of various climatic hazards. During 43-day pollution period, 5 types of temperature inversion were created in Tehran City, with subsidence and subsidence-frontal inversions playing dominant roles in intensifying pollution and its duration, respectively. Wind direction during the whole period was southern to northwestern (predominantly western), which helped in transporting the air pollutants generated by industries in western part of Tehran City to other regions. An analysis of cloud conditions showed the absence of clouds in Tehran's sky on most polluted days. Furthermore, on the other days, a very low cloud thickness was observed at levels above $700 \mathrm{hPa}$. An analysis of more than 20 instability indices using data from the University of Wyoming revealed weak intensities in the polluted days. According to results of the studied indices, a calm and dry descending atmosphere was mainly dominant controlling concentration and increase in pollution density, and influencing consequent occurrence and continuity of the pollution period. An analysis of sources and entry routes of the polluted air and airflow via HYSPLIT models showed that during peak days of the pollution period, formation of southwestern and western airflow from desert regions of southern Iraq and arid region of Central Iran played an important role in increasing concentrations of pollutants and continuity of pollution period across Tehran City. The most long-lasting clean air 
period was determined by considering an AQI of 50 and below, and its synoptic conditions were compared with those of the selected long-lasting pollution period. The longest clean air period in Tehran City occurred from March 24 to April 4, 2019, with corresponding average AQI of 50 or less. The sea-level pressure map showed penetration of Mediterranean and Saudi Arabian multi-core low-pressures and extension of deep trough in middle level of atmosphere on Iran. These conditions caused advection of rising and diverging warm and humid airflow from water sources to south of Iran toward eastern and frontal parts of the trough, resulting in severe precipitation during this period in the country and the region under study. Consequently, pollution density reached its lowest level, creating the longest clean air period over a 10-year time span (2010-2019) for Tehran metropolis. Wind direction from southwest to northwest and from industrial cluster in western half of Tehran City transported pollution from industries to Tehran City, and dissipation of the polluted air in the city was prevented by high mountains to north and east of the city (Farhadi et al. 2018). Transferring Tehran's polluting industries out of the city to eastern and southeastern regions, improving fuel quality, replacing new vehicles with old ones (Delkash and Mir 2016), increasing the use of public transportation, and reducing the use of private cars can greatly mitigate pollution crisis experienced in Tehran City.

\section{Declarations}

Conflict of interest The authors declare that they have no conflict of interest.

\section{References}

Adame JA, Hernandez-Ceballos MA, Bolívar JP, Dela Morena B (2012) Assessment of an air pollution event in the southwestern Iberian Peninsula. Atmos Environ 55:245-256. https://doi.org/10.1016/j. atmosenv.2012.03.010

Air Resources Laboratory (ARL) USA (2019) Hybrid single particle lagrangian integrated trajectory. https://ready.arl.noaa.gov/HYSPLIT.php. Accessed 17 Mar 2020

Alijani B (2007) Iran climate. Payam Noor, Tehran

Alijani B (2002) Weather types and their effects on climate in Iran. Kavoshnameh 3:21-50

Arkian F, Nicholson SE (2018) Long-term variations of aerosol optical depth and aerosol radiative forcing over Iran based on satellite and AERONET data. Environ Monit Assess 190:1-15. https://doi.org/10. 1007/s10661-017-6336-1

Ashrafi K, Shafiepour-Motlagh M, Aslemand A, Ghader S (2014) Dust storm simulation over Iran using HYSPLIT. J Environ Health Sci Eng 12:1-9. https://doi.org/10.1186/2052-336X-12-9

Baltaci H, Sinem C, Alemdar O, Akkoyunlu BO (2020) Background atmospheric conditions of high PM $\mathrm{PM}_{10}$ concentrations in Istanbul. Turkey Atmos Poll Res 11(9):1524-1534. https://doi.org/10.1016/j.apr. 2020.06.020

Bednorz E, Tomczyk AM (2021) Influence of macroscale and regional circulation patterns on low- and high-frequency sea level variability in the Baltic Sea. Theor Appl Climatol 144:115-125. https://doi. org/10.1007/s00704-020-03500-0

Bidokhti A, Shariepour Z (2010) Meteorological conditions of acute air pollution episodes for Tehran. J Environ Stud 35(52):1-14 (in Persian)

Cerrato-Alvarez M, Núñez-Corchero M, Miró-Rodríguez C, Pinilla-Gil E (2019) Synoptic circulation patterns and local sources associated to high concentrations of tropospheric ozone in rural and suburban areas in southwestern Spain. Air Qual Atmos Health 13:97-108. https://doi.org/10.1007/ s11869-019-00774-w

Cuell C, Bonsal B (2009) An assessment of climatological synoptic typing by principal component analysis and kmeans clustering. Theor Appl Climatol 98:361-373. https://doi.org/10.1007/s00704-009-0119-8 
Darand M, Pazhoh F (2019a) Synoptic analysis of sea level pressure patterns and Vertically Integrated Moisture Flux Convergence VIMFC during the occurrence of durable and pervasive rainfall in Iran. Dynam Atmos Oceans 86:10-17. https://doi.org/10.1016/j.dynatmoce.2019.02.004

Darand M, Pazhoh F (2019b) Vertically integrated moisture flux convergence over Iran. Clim Dyn 53:35613582. https://doi.org/10.1007/s00382-019-04726-z

Delkash M, Mir HM (2016) Examining some potential actions in mitigating gaseous emissions from vehicles, case study: Tehran. Air Qual Atmos Health 9:909-921

Di Y, Li R (2019) Correlation analysis of AQI characteristics and meteorological conditions in heating season. IOP Conf Ser Earth Environ Sci. https://doi.org/10.1088/1755-1315/242/2/022067

Draxler R, Ginoux P, Stein AF (2007) An empirically derived emission algorithm for wind-blown dust. J Geophys Res 115:D16212. https://doi.org/10.1029/2009JD013167

Farhadi R, Hadavifar M, Moeinaddini M, Amintoosi M (2018) Sensitivity analysis of meteorological parameters and instability indices on concentration of carbon monoxide, particulate matter, and air quality index in Tehran. Ecopersia 6(2):91-100

Fiddes SL, Pezza AB, Mitchell TA, Kozyniak K, Mills D (2016) Synoptic weather evolution and climate drivers associated with winter air pollution in New Zealand. Atmos Pollut Res 7(6):1082-1089. https:// doi.org/10.1016/j.apr.2016.06.014

Finardi S, Pellegrini U (2002) Systematic analysis of meteorological conditions causing severe urban air episodes in the central Po valley. In: 9th conference on harmonisation within atmospheric dispersion modelling for regulatory purposes, pp 250-254

Gao H, Chen J, Wang B, Tan S, Lee olin M, Yao X, Yan H, Shi J (2011) A study of air pollution of city clusters. Atmos Environ 45:3069-3077. https://doi.org/10.1016/j.atmosenv.2011.03.018

Ghorani-Azam A, Riahi-Zanjani B, Balali-Mood M (2016) Effects of air pollution on human health and practical measures for prevention in Iran. J Res Med Sci 21:65-77

Gope S, Dawn S, Das SS (2021) Effect of COVID-19 pandemic on air quality: a study based on Air Quality Index. Environ Sci Pollut Res. https://doi.org/10.1007/s11356-021-14462-9

Hejazizadeh Z, Pazhoh F, Jafari F (2019) The relationship between severe and pervasive droughts and wet years in half east of iran with synoptic troposphere condition. Geogr Environ Hazards 7(3):160-135. https://doi.org/10.22067/geo.v0i0.68353

Holton J (2012) An introduction to dynamic meteorology. Academic, Cambridge

Hosseinzadeh SR, Doostan R, Haghighat-Ziabary SM, Haghighat-Ziabari SM (2013) The study of synoptic patterns of air pollution in Mashhad metropolis. J Geogr Reg Dev 11(21):81-102. https://doi.org/10. 22067/geography.v11i21.36332

Jamaati H, Attarchi M, Hassani S, Elham-Farid E, Seyedmehdi SM, Salimi P (2018) Investigating air quality status and air pollutant trends over the Metropolitan Area of Tehran, Iran over the past decade between 2005 and 2014. Environ Health Toxicol 32(2):1-7. https://doi.org/10.5620/eht.e2018010

Kalkstein LS, Tan G, Skindlov JA (1987) An evaluation of three clustering procedures for use in synoptic climatological classification. J Clim Appl Meteorol 26(6):717-730

Kalnay E, Kanamitsu M, Kistler R, Collins W, Deaven D, Gandin L, Iredell M, Saha S, White G, Whoollen J, Zhu Y, Leetmaa A, Reynolds B, Chelliah M, Ebisuzaki W, Higgins W, Janowiak J, Mo KC, Ropelewski C, Wang J, Jenne R, Joseph D (1996) The NCEP/NCAR 40 year reanalysis project. Bull Am Meteorol Soc 77:437-471. https://doi.org/10.1175/1520-0477(1996)077\%3c0437:TNYRP\%3e2.0. $\mathrm{CO} ; 2$

Karami S, Ranjbar-SaadatAbadi A, Mohebalhojeh AR, Moradi M (2017) A rare case of haboob in Tehran: observational and numerical study. Atmos Res 185:169-185. https://doi.org/10.1016/j.atmosres.2016. 10.010

Karimzadegan H, Rahmatian M, Farhud DD, Yunesian M (2008) Economic valuation of air pollution health impacts in the Tehran Area, Iran. Iran J Publ Health 37(1):20-30

Kermani M, Dowlati M, Jafari AJ, Rezaei R, Kalantari RR, Sakhaei FS (2018) Study of number of total mortality, cardiovascular and respiratory mortality attributed to air pollutants of Tehran in 2005-2014. Global Nest J 20(3):439-448. https://doi.org/10.30955/gnj.002459

Khansalari S, Ghobadi N, Aliakbari-Bidokhti A, Fazel-Rastgar F (2020) Statistical classification of synoptic weather patterns associated with Tehran air pollution. J Air Pollut Health 5(1):43-62. https://doi.org/ 10.18502/japh.v5i1.2858

Khoshhal-Dastjerdi J, Mousavi S, Kashki A (2012) Synoptic analysis of Ilam dust storms (1987-2005). Geography Environ Plan 23(2):15-34 (in Persian)

Kistler R, Collins W, Saha S, White G, Woollen Chelliah MJ, Ebisuzaki W, Kanamitsu M, Kousky V, Van den Dool H, Jenne R, Fiorino M (2001) The NCEP/NCAR 50 year reanalyses: monthly vanden Dool H Jenne R CD-ROM and documentation. Bull Am Meteorol Soc 82:247-267. https://doi.org/10.1175/ 1520-0477(2001)082<0247:TNNYRM >2.3.CO;2 
Lashkari H, Hedayat P (2006) Synoptic analysis of Severe inversions' pattern of Tehran. Geores 56:6582 (in Persian)

Liu J, Mauzerall DL, Chen Q, Zhang Q, Song Y, Peng W, Klimont Z, Qiu X, Zhang S, Hu M, Lin W, Kirk R (2016) Air pollutant emissions from Chinese households: a major and underappreciated ambient pollution source. Proc Natl Acad Sci USA 113:7756. https://doi.org/10.1073/pnas.16045 37113

Liu S, Yan Z, Liu Y, Yin Q, Kuang L (2017) Association between air pollution and chronic diseases among the elderly in China. Nat Hazards 89:79-91. https://doi.org/10.1007/s11069-017-2955-7

Lou J, Wu Y, Liu P, Kota SH, Huang L (2019) Health effects of climate change through temperature and air pollution. Curr Pollution Rep 5:144-158. https://doi.org/10.1007/s40726-019-00112-9

Magari SR, Hauser R, Schwartz J, Williams PL, Smith TJ, Christiani DC (2001) Association of heart rate variability with occupational and environmental exposure to particulate air pollution. Circulation 104(9):986-991. https://doi.org/10.1161/hc3401.095038

Mansouri-Daneshvar MR, Ebrahimi M, Nejadsoleymani H (2019) An overview of climate change in Iran: facts and statistics. Environ Syst Res 8:7. https://doi.org/10.1186/s40068-019-0135-3

Mashat AW, Awad A (2016) Synoptic characteristics of the primary widespread winter dust patterns over the northern Arabian Peninsula. Air Qual Atmos Health 9:503-516. https://doi.org/10.1007/ s11869-015-0357-0

Mawer C (2014) Air pollution in Iran. BMJ. https://doi.org/10.1136/bmj.g1586

Meshkini A, Azadi Ghatar S, Roknoldin Eftekhari A, Mostafavi E, Ahadnejad-Reveshti M (2017) Spatial and Chronological Analysis of Deaths from Gastric Cancer in Tehran. GeoRes 31(4):7-23

Moradi M, Ranjbar-SaadatAbadi R (2019) Case study of flood rainfall in March 2019. Nivar 43:71-87. https://doi.org/10.30467/nivar.2019.90510

Mousavi A, Ardalan A, Takian A, Ostadtaghizadeh A, Naddafi K, Massah Bavani A (2020) Climate change and health in Iran: a narrative review. J Environ Health Sci Eng 18:367-378. https://doi.org/ $10.1007 / \mathrm{s} 40201-020-00462-3$

Munoz RC, Corral MJ (2017) Surface indices of wind, stability, and turbulence at a highly polluted urban site in Santiago, Chile, and their relationship with nocturnal particulate matter concentrations. Aerosol Air Qual Res 17:2780-2790. https://doi.org/10.4209/aaqr.2017.05.0190

NOAA Earth System Research Laboratories (ESRL) (2019) Synoptic analyze the network data. https:// psl.noaa.gov/data/gridded/data.ncep.reanalysis.html. Accessed 20 Jan 2020

Perkins HC (1974) Air Pollution. McGraw-Hill, New York

Rainham DG, Smoyer-Tomic KE, Sheridan SC, Burnett RT (2005) Synoptic weather patterns and modification of the association between air pollution and human mortality. J Environ Heal R 15(5):347360. https://doi.org/10.1080/09603120500289119

Ramezani NA, Alijani B, Borna R (2018) Explaining the effects of climate elements in Tehran's metropolis air quality. GeoRes 33(3):154-169

Ranjbar-Saadat Abadi A, Azadi M, Bidokhti AA, Sadeghi Hosseini SA (2005) A case study of heat island of Tehran city and its numerical simulation. Earth Space Phys 31(1):63-78 (in Persian)

Ranjbar-Saadatabadi A, Azizi G (2012) Studying of meteorological patterns, identifying of dust sources and motion track of particles for dust storm, July 2009. Phys Geog Res 44(3):73-92. https://doi.org/ 10.22059/jphgr.2012.29215

Ravindra K, Mittal AK, Grieken RV (2001) Health risk assessment of urban suspended particulate matter with special reference to polycyclic aromatic hydrocarbons: a review. Rev Environ Health 16(3):169-89. https://doi.org/10.1515/reveh.2001.16.3.169

Rezaei M, Farajzadeh M, Mielonen T, Ghavidel Y (2018) Analysis of spatio-temporal dust aerosol frequency over Iran based on satellite data. Atmos Pollut Res 10(2):508-519. https://doi.org/10. 1016/j.apr.2018.10.002

Rolph G, Stein A, Stunder B (2017) Real-time environmental applications and display system: READY. Environ Model Softw 95:210-228. https://doi.org/10.1016/j.envsoft.2017.06.025

Saniei R, Zangiabadi A, Sharifikia M, Ghavidel Y (2016) Air quality classification and its temporal trend in Tehran, Iran, 2002-2012. Geospat Health 11(2):442. https://doi.org/10.4081/gh.2016.442

Stein AF, Draxler RR, Rolph G, Stunder BJB, Cohen MD, Ngan F (2015) NOAA's HYSPLIT atmospheric transport and dispersion modeling system. Bull Am Meteor Soc 96:2059-2077. https://doi. org/10.1175/BAMS-D-14-00110.1

Stunder BJB (1997) NCEP model output-FNL archive data, prepared for national climatic data center (NCDC) report TD-6141. National Climatic Data Center, Washington. https://www.ready.noaa.gov/ fnl.php. Accessed 19 Sept 2020.

Taghizadeh F, Jonidi-Jafari A, Kermani M (2019) The trend of air quality index (AQI) in Tehran during (2011-2016). J Air Pollution Health 4(3):187-192. https://doi.org/10.18502/japh.v4i3.1548 
Tierney G, Robinson WA, Lackmann G, Miller R (2021) The sensitivity of persistent geopotential anomalies to the climate of a moist channel model. J Clim 34(12):5093-5108. https://doi.org/10.1175/ JCLI-D-20-0254.1

Tavousi T, Hossein-Abadi N (2017) Evaluation of temperature inversion indicators in boundary layer (Case Study: Tehran, Iran). Geores 32(2):120-132

Tehran Air Quality Control Company (2019) Daily data of AQI index. http://airnow.tehran.ir/home/AirQu ality.aspx. Accessed 25 Dec 2019.

Univesity of Wyoming (2019) Upperair air data. http://weather.uwyo.edu/upperair/sounding.html. Accessed 14 Apr 2020.

USEPA (2014) Air quality index: a guide to air quality and your health. Environmental Protection Agency, Washington DC

Vaghefi SA, Keykhai M, Jahanbakhshi F, Sheikholeslami J, Ahmadi A, Yang H, Abbaspour KC (2019) The future of extreme climate in Iran. Sci Rep 9:1464. https://doi.org/10.1038/s41598-018-38071-8

Vardoulakis S, Kassomenos P (2008) Sources and factors affecting PM10 levels in two cities: European implications for local air quality management. Atmos Environ 42(17):3949-3963. https://doi.org/10. 1016/j.atmosenv.2006.12.021

Wu X, Chen Y, Guo J, Wang G, Gong Y (2017) Spatial concentration, impact factors and preventioncontrol measures of $\mathrm{PM}_{2.5}$ pollution in China. Nat Hazards 86:393-410. https://doi.org/10.1007/ s11069-016-2697-y

Yicun G, Khorshiddoust AM, Mohammadi GH, Hoseini-Sadr A, Aghlmand F (2020) The relationship between $\mathrm{PM}_{2.5}$ concentrations and atmospheric conditions in severe and persistent urban pollution in Tabriz, northwest of Iran. Arab J Geosci 13:202. https://doi.org/10.1007/s12517-020-5128-Z

Zhou C, Wei G, Xiang J, Zhang K, Li C, Zhang J (2018) Effects of synoptic circulation patterns on air quality in Nanjing and its surrounding areas during 2013-2015. Atmos Pollut Res 9(4):723. https://doi.org/ 10.1016/j.apr.2018.01.015

Publisher's Note Springer Nature remains neutral with regard to jurisdictional claims in published maps and institutional affiliations. 